\title{
Surface/bulk partitioning and acid/base speciation of aqueous decanoate: direct observations and atmospheric implications
}

\author{
N. L. Prisle ${ }^{1}$, N. Ottosson ${ }^{2}{ }^{*}$, G. Öhrwall ${ }^{3}$, J. Söderström ${ }^{2}$, M. Dal Maso ${ }^{1}$, and O. Björneholm ${ }^{2}$ \\ ${ }^{1}$ University of Helsinki, Department of Physics, P.O. Box 48, 00014, University of Helsinki, Helsinki, Finland \\ ${ }^{2}$ University of Uppsala, Department of Physics and Astronomy, Box 516, 75120, Uppsala, Sweden \\ ${ }^{3}$ University of Lund, MAX-lab, Box 118, 22100, Lund, Sweden \\ * now at: FOM Institute AMOLF, Science Park 104, 1098 XG Amsterdam, The Netherlands
}

Correspondence to: N. L. Prisle (nonne.prisle@helsinki.fi)

Received: 27 April 2012 - Published in Atmos. Chem. Phys. Discuss.: 15 May 2012

Revised: 12 December 2012 - Accepted: 13 December 2012 - Published: 21 December 2012

\begin{abstract}
Dilute aqueous solutions of the atmospheric organic surfactant sodium decanoate have been studied using surface sensitive X-ray photoelectron spectroscopy combined with synchrotron radiation. We studied the decanoate/decanoic acid speciation and preferential adsorption at the vapor-liquid interface, and the responses to mixing in solution with some of the most common atmospheric inorganic ions, $\mathrm{Na}^{+}, \mathrm{NH}_{4}^{+}, \mathrm{Cl}^{-}$, and $\mathrm{SO}_{4}^{2-}$. We observe little or no influence of $\mathrm{Na}^{+}, \mathrm{Cl}^{-}$, or $\mathrm{SO}_{4}^{2-}$ ions, on neither the relative speciation nor the individual adsorption properties of decanoate and decanoic acid. In particular, no significant salting-out effect due to common $\mathrm{Na}^{+}$cations of the organic and inorganic salts was observed for these solutions. On the other hand, mixing with $\mathrm{NH}_{4}^{+}$cations resulted in a pronounced surface enhancement of decanoic acid, which is attributed to surface specific acid-base chemistry. These changes in surface/bulk partitioning and surface speciation may significantly affect properties of aqueous droplets containing decanoate/decanoic acid, and potential implications for several processes critical to the climate effects of atmospheric aerosols are discussed.
\end{abstract}

\section{Introduction}

Aerosol effects still constitute the greatest uncertainties in assessing anthropogenic contributions to global climate change (IPCC, 2007). Both direct and indirect climate effects of atmospheric aerosol particles are governed by their numbers, sizes, and chemical properties. Particles in the atmosphere are typically fairly even mixtures of both organic and inorganic species (O'Dowd et al., 2004; Murphy et al., 2006; Zhang et al., 2007). In addition, particles may absorb water from the air, to maintain equilibrium of condensed phase water activity $\left(a_{\mathrm{w}}\right)$ at a given ambient humidity, according to the generalized Raoult's Law (Prisle et al., 2010b, e.g., and references therein). Including interactions with water, as well as effects of mutual interactions between individual particle components within the aqueous phase, is therefore essential to considerations of atmospheric aerosol properties. Properly describing such interactions nevertheless poses many challenges yet to be met, owing to the vast number of chemical species and the wide ranges of their concentrations and relative mixing states observed in the atmosphere, just as the miniscule amounts of material present in submicrometer aerosols prevent direct observations of many crucial properties.

A great many of the organic compounds identified in the atmospheric particle phase are known, or expected from their molecular structures, to be surface active in aqueous solutions. This means that these molecules preferentially adsorb at the surface, where they may reduce the surface tension, compared to pure water. Such surface active molecules (surfactants) have been observed directly, and indirectly via their effects on sample surface tension, in bulk samples of atmospheric cloud and fog waters, as well as in aerosol samples and their aqueous extracts, from a wide range of environments. Fatty acids $\left(\mathrm{CH}_{3}\left(\mathrm{CH}_{2}\right)_{\mathrm{n}} \mathrm{COOH}\right)$ and their carboxylate anion corresponding bases $\left(\mathrm{CH}_{3}\left(\mathrm{CH}_{2}\right)_{\mathrm{n}} \mathrm{COO}^{-}\right)$constitute an important class of known atmospheric surfactants 
(Facchini et al., 1999, 2000; Mochida et al., 2002; Cheng et al., 2004; Kiss et al., 2005; Dinar et al., 2006). Their surface activity in aqueous solution stems from hydrophobic interactions of the aliphatic carbon chain with the polar water molecules.

In this work, we address physico-chemical properties related to the surfaces of aqueous solutions comprising surface active organics mixed with inorganics. For aerosol systems in such solution phases, an important aspect of aqueous-phase interactions between organic and inorganic components are manifested in the salting-out or -in of organics with finite solubility by inorganic salts (Gill et al., 1983; Lin et al., 2005; Tuckermann, 2007). These phenomena are anticipated to further affect the properties of mixed atmospheric aerosols (Tabazadeh, 2005; Vanhanen et al., 2008) and have therefore on occasion been invoked to explain deviations from thermodynamic predictions observed for ambient or experimental model aerosol systems. On the molecular scale, there has recently been much progress examining multi-component solution structure at the liquid-vapor interface of solutions utilizing techniques such as XPS and scattering on liquid jets, and nonlinear spectroscopy. In particular relevance for the present work, surface segregation and speciation of inorganic and organic acids has been studied using XPS, indicating an increased surface propensity of the acid (protonated) forms (Ottosson et al., 2011b; Lewis et al., 2011). The interaction of gas phase species with pure and complex liquid surfaces, and subsequent processes such as solvation and dissociation has been studied in molecular beam scattering experiments (Nathanson, 2004; Burden et al., 2009; Dempsey et al., 2011). Non-linear spectroscopic techniques have been used to study phenomena such as molecular ordering at the interface between water and charged surfactants (Gragson et al., 1996), the possible propensity of simple inorganic ions to alcohol/water (Onorato et al., 2010) and carboxylate/water (Tang and Allen, 2009) interfaces, and competition and oxidation of fatty acids spread at the air/water interface (Voss et al., 2006). However, the underlying molecular level interactions are still not sufficiently well-known for most atmospherically relevant aqueous solution compositions, from either experimental or theoretical approaches. The detailed nature and magnitude of salting-out effects in atmospheric aerosols thus remain speculative.

The surface activity of dissolved components in aqueous aerosol and the nature of functional groups present at the solution-air interface may significantly affect a number of climatically important aerosol properties. For example, the cloud droplet formation of organic aerosols is affected by surface activity via both the influence of surface/bulk partitioning on bulk phase water activity and surface tension reduction in aqueous droplets (Sorjamaa et al., 2004). These mechanisms are however intricately and non-linearly connected, and the overall influence of surface activity on cloud droplet activation and resulting cloud properties is not readily anticipated (Prisle et al., 2008, 2010b, 2012). Analogously, properties of solutes dissolved in the bulk phase can also be expected to influence the freezing of aqueous droplets in the atmosphere. The mechanisms involved however still remain to be properly constrained. Surface adsorption of aerosol constituents with varying chemical functionalities may influence heterogeneous chemistry at the particle surfaces, towards both gas phase and aerosol condensed phase reactants. Formation of organic films on aqueous aerosol surfaces could in addition affect gas-particle mass transfer of water and semi-volatile aerosol components. All of these processes are directly related to cloud formation, precipitation, and cloud processing in the atmosphere and consequently expected to affect the formation, composition, microphysics, processing, transport, and eventual removal of atmospheric organic aerosols, and thus ultimately both the direct and indirect aerosol climate effects.

We here specifically study the speciation of an atmospheric organic surfactant, sodium decanoate $\left(\mathrm{CH}_{3}\left(\mathrm{CH}_{2}\right)_{8} \mathrm{COONa}\right.$; DecNa), in terms of the relative abundances of the decanoate anion $\left(\mathrm{CH}_{3}\left(\mathrm{CH}_{2}\right)_{8} \mathrm{COO}^{-}\right.$; $\left.\mathrm{Dec}^{-}\right)$ and the corresponding decanoic acid $\left(\mathrm{CH}_{3}\left(\mathrm{CH}_{2}\right)_{8} \mathrm{COOH}\right.$; $\mathrm{DecH})$ in the aqueous solution surface phase. Similar fatty acid systems are known to have the carboxylate/carboxylic group coordinated to water and the aliphatic hydrocarbon tail sticking out of the water. The orientation of the tails changes from somewhat tilted to more perpendicular conformations with respect to the surface plane upon increasing surface coverage (Kjaer et al., 1989; Guyot-Sionnest et al., 1987). We are not aware of any specific study of the orientation of the decanoic/decanoate species at the water surface, but we consider it reasonable to assume that they behave similarly. This notion was also invoked by Lunkenheimer and Hirte (1992); Hirte and Lunkenheimer (1996); Earnshaw et al. (1996) and shown to agree with measured aqueous surface tensions for decanoic acid according to theoretical adsorption isotherms. We further investigate how these surface abundances are affected by mixing in the aqueous phase with salts comprising some of the most common inorganic ions found in atmospheric aerosols (e.g., Seinfeld and Pandis, 2006), specifically sodium chloride $(\mathrm{NaCl})$, sodium sulfate $\left(\mathrm{Na}_{2} \mathrm{SO}_{4}\right)$, ammonium sulfate $\left(\left(\mathrm{NH}_{4}\right)_{2} \mathrm{SO}_{4}\right)$ and ammonium chloride $\left(\mathrm{NH}_{4} \mathrm{Cl}\right)$.

The bulk-phase distribution between the two corresponding carboxylic acid/carboxylate forms depends on intrinsic acid strength, as given by the acid constant

$$
K_{\mathrm{a}}(\mathrm{DecH})=\frac{\left[\mathrm{Dec}^{-}\right]_{(\mathrm{aq})}\left[\mathrm{H}_{3} \mathrm{O}^{+}\right]_{(\mathrm{aq})}}{[\mathrm{DecH}]_{(\mathrm{aq})}}
$$

according to the protolysis equilibrium

$\operatorname{DecH}_{(\mathrm{aq})}+\mathrm{H}_{2} \mathrm{O} \leftrightharpoons \operatorname{Dec}^{-}{ }_{(\mathrm{aq})}+\mathrm{H}_{3} \mathrm{O}^{+}{ }_{(\mathrm{aq})}$

as well as solution concentration, $\mathrm{pH}$, and general mixing state. The $\mathrm{Dec}^{-}$and $\mathrm{DecH}$ forms have different aqueous bulk 
solubilities and surface adsorption properties; DecH being much less soluble and much more surface active than $\mathrm{Dec}^{-}$ (Campbell and Lakshminarayanan, 1965; Fainerman et al., 2002; Lide, 2004; Luepakdeesakoon et al., 2006). We expect that these properties may in turn be affected differently for $\mathrm{Dec}^{-}$and $\mathrm{DecH}$, respectively, upon mixing with inorganic solutes in the aqueous solution.

\section{Methods}

Aqueous solution surfaces were studied directly using synchrotron radiation based X-ray photoelectron spectroscopy (XPS), a highly surface and chemically sensitive spectroscopic technique (Hüfner, 1995). Due to their high vapor pressure, aqueous systems have previously been difficult to study with XPS, which needs to be performed in vacuum. These problems were recently solved with the liquid jet technique (Winter and Faubel, 2006, e.g., and references therein), thus allowing XPS to be used for the study of systems with compositions immediately resembling those of aqueous atmospheric aerosol. Minimum concentrations possible to study with the liquid jet + XPS technique depend on factors such as surface propensity and ionization cross section. Ionization cross sections vary with several orders of magnitude between different elements, different orbitals in the same element, and photon energy (Yeh and Lindau, 1985). For the case of $\mathrm{C} 1 \mathrm{~s}$ orbitals and no surface enrichment of the investigated species, a minimum concentration for practical measurements may be around $0.05 \mathrm{M}$, whereas surface enrichment may make measurements at concentrations orders of magnitude lower practically feasible. Since all samples studied in this work contain ionic charge carriers, the results are not influenced by sample charging during measurements. The probing depth of the XPS measurements depends on the mean free path for inelastic scattering of the outgoing photoelectrons, which for the kinetic energies used here is in the range of a few Ångströms. This means that 25-75\% of the signal will come from the outermost molecular layer, and the remainder, 75-25\%, from deeper down in the sample (Powell and Jablonski, 2009). The method is therefore ideal for specifically probing adsorption of dissolved surfactant species at the vapor-liquid interface.

Regarding chemical sensitivity, XPS is in particular for the present study capable of discriminating between signals originating from the protonated and deprotonated carboxylic groups (Ottosson et al., 2011b), respectively, and hence between the two different molecular forms comprising the corresponding decanoate/decanoic acid pair. To illustrate the chemical sensitivity of XPS, an idealized spectrum for an aqueous mixture of $\mathrm{Dec}^{-}$and $\mathrm{DecH}$, based on earlier results for carboxylic acids (Ottosson et al., 2011b), is shown in Fig. 1. The ordinate gives the electron binding energy in the $\mathrm{C} 1 \mathrm{~s}$ region (note that the scale increases from right to left). For the energy region displayed, signals

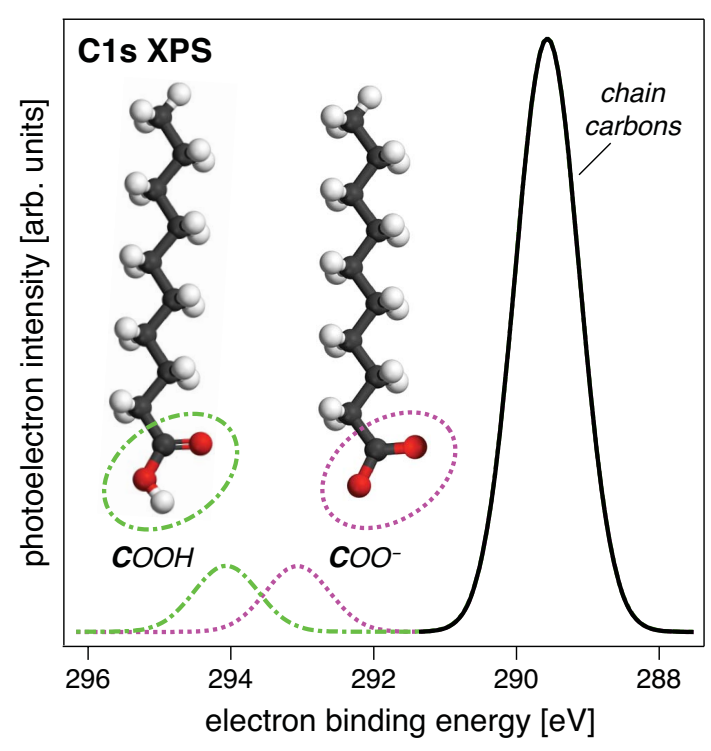

Fig. 1. Schematic representation of an X-ray photoelectron spectrum of aqueous decanoate/decanoic acid in the $\mathrm{C} 1 \mathrm{~s}$ region, showing, for increasing binding energy (from right to left ordinate), idealized signals (on an arbitrary scale abscissa) originating from aliphatic (methyl and methylene), carboxylate, and carboxylic carbons, respectively. The electron binding energy shifts for the aliphatic carbons are much smaller than for the carboxyl carbon upon (de)protonation, and have been neglected in this figure.

of detected electrons are shown (using an arbitrary scale) on the abscissa, originating from the chemically inequivalent aliphatic (methyl and methylene), carboxylate, and carboxylic carbons, respectively. For free, randomly oriented decanoic acid molecules, the intensity ratio between the carboxylate/carboxylic carbon and the aliphatic chain carbons would be close to the stoichiometric ratio, i.e. $1: 9 \approx 0.11$. This ratio can, in some cases where elastic scattering of the outgoing photoelectron is significant, divert from the stoichiometric value (Söderström et al., 2012). For $\mathrm{Dec}^{-}$and $\mathrm{DecH}$ these effects are most likely negligible and we do not consider them here. The $\mathrm{C}$ 1s electron binding energy of the carboxylic acid group is larger than that of the carboxylate group, because the $\mathrm{C} 1 \mathrm{~s}$ electrons are more tightly bound in the neutral environment of the protonated carboxyl group than in the negatively charged de-protonated carboxylate group. We primarily focus on the $\mathrm{C} 1 \mathrm{~s}$ signal from the carboxylate/carboxylic group, as this a sensitive fingerprint of the protonation degree, and to a lesser extent use the intensity ratio between the aliphatic chain and carboxylate/carboxylic signals.

The liquid-jet photoelectron experiments were performed at the Swedish national synchrotron facility MAX-lab in Lund, at the soft X-ray undulator beamline I411 (Bässler et al., 1999). The experimental setup has previously been described in detail (Bergersen et al., 2007). Briefly, the liquid samples were injected through a nozzle with diameter 
Table 1. Basic properties of the organic and inorganic salts used for sample preparation: molecular formula, molar mass $\left(M\left[\mathrm{~g} \mathrm{~mol}^{-1}\right]\right)$, and number of ions per formula unit (v).

\begin{tabular}{lcc}
\hline Formula & $M\left[\mathrm{~g} \mathrm{~mol}^{-1}\right]$ & $v$ \\
\hline $\mathrm{CH}_{3}\left(\mathrm{CH}_{2}\right)_{8} \mathrm{COONa}(\mathrm{DecNa})$ & 194.247 & 2 \\
$\mathrm{NaCl}$ & 58.4428 & 2 \\
$\mathrm{Na}_{2} \mathrm{SO}_{4} \cdot 10 \mathrm{H}_{2} \mathrm{O}$ & 322.2 & 3 \\
$\left(\mathrm{NH}_{4}\right)_{2} \mathrm{SO}_{4}$ & 132.1 & 3 \\
$\mathrm{NH}_{4} \mathrm{Cl}$ & 53.49 & 2 \\
\hline
\end{tabular}

of $20 \mu \mathrm{m}$ into an evacuated experimental chamber, forming a jet travelling at a velocity of approximately $25 \mathrm{~m} \mathrm{~s}^{-1}$. The ionization occurred within a few millimeters after injection, well before the jet breaks up into droplets, and eventually the liquid was frozen out in a liquid nitrogen cold trap. The liquid jet has a temperature of approximately $10^{\circ} \mathrm{C}$ as it leaves the nozzle, after which it starts to cool due to evaporation. The jet does remain liquid at least until it starts to break up up into droplets, and as the measurements are performed on the jet part and not the droplet part, we estimate the temperature of the liquid during measurements to be $5 \pm 5^{\circ} \mathrm{C}$. The expelled electrons entered the analyzer through a circular opening with a diameter of $0.5 \mathrm{~mm}$, situated approximately $1 \mathrm{~mm}$ from the liquid surface. This allowed for good differential pumping of the spectrometer, while a sufficient fraction of the photoelectrons were passed through the vapor without undergoing inelastic scattering which would change their apparent binding energy. A Scienta R4000 hemispherical electron analyzer was mounted perpendicular to the flow of the liquid jet, at $54.7^{\circ}$ (the magic angle) relative to the polarization plane of the linearly polarized synchrotron radiation, in order to minimize angular distribution effects on the resulting spectra (Hüfner, 1995). The total experimental resolution (as determined from the width of the gas phase water $1 b_{1}$ state) at the photon energy of $360 \mathrm{eV}$ used for the $\mathrm{C} 1 \mathrm{~s}$ measurements was better than $250 \mathrm{meV}$. This is significantly less than the inherent width of the investigated photoelectron lines for the aqueous species in question, meaning that the experimental resolution is not a limiting factor of the measurements. The spectra were calibrated, regarding binding energy by using that of the liquid water $1 b_{1}$ orbital as reference (Winter et al., 2004), and regarding intensity by normalizing to ring current, which is proportional to the photon flux and measurement time.

The investigated systems were aqueous solutions of sodium decanoate, as pure solute (binary), and mixed solute (ternary) with one of the inorganic salts sodium chloride, sodium sulfate, ammonium sulfate, and ammonium chloride. Each solute or solute mixture was studied at two different concentrations, corresponding to approximately 25 and $10 \mathrm{mM}$ of DecNa, respectively. Details of the sample preparation procedure are given in the Supplement (S1). Specifics of the organic and inorganic solutes are given in Table 1 and properties of the investigated solutions in Table 2. All samples were of high purity, and control experiments without decanoate (see Supplement S2) showed no detectable carbon contamination from the water, salts, or the sample handling equipment. We observe upon sample preparation that the more concentrated solutions are close to the critical micelle concentration $(\mathrm{cmc})$ or solubility limit for DecNa in the ternary solutions. This is consistent with the $\mathrm{cmc}$ value of $94 \mathrm{mM}$ given for binary aqueous DecNa at $25^{\circ} \mathrm{C}$ by Campbell and Lakshminarayanan (1965), whence the cmc for a ternary solution with higher ionic strength (see Sect. 3.1 below) is expected to be lower. The liquid jet technique requires solutes to be fully solvated in the sample solution. As aqueous bulk solubility may decrease with temperature, solutes may precipitate when the jet is gradually cooled in the evacuated chamber. Measurements are therefore typically restricted to below $\sim 80 \%$ of the cmc or solubility limit. The investigated solutions thus give a representative span of the concentration region where liquid jet measurements are feasible and give a good signal for the species in question. The surfactant DecNa has sufficiently high water solubility and low vapor pressure to facilitate the experimental handling, and sufficiently high surface activity to for us to anticipate detectable effects of the investigated mechanisms. Of many potentially interesting compounds, we therefore chose DecNa for this study, based on knowledge from prior studies of an advantageous combination of properties making it a good model system for the present purposes (Prisle et al., 2008, 2010b).

Experiments were conducted at several occasions. The results presented in this paper were reproducibly observed in independent sets of experiments.

\section{Results and discussion}

Results of the liquid-jet experiments are shown in Figs. 2 and 3. Each of the figures presents core photoelectron spectra recorded in the energy region relevant for the carboxylate and carboxylic acid $\mathrm{C} 1 \mathrm{~s}$ electrons. The spectra display photoelectron signal intensity (on an arbitrary scale) as a function of core electron binding energy. The measured spectra are presented in two separate figures due to experimental conditions; for the spectra in Fig. 2, alignment of the XPS setup was maintained between the individual experiments presented in each panel and the recorded photoelectron signal intensities can therefore be immediately compared. The alignment was not maintained between recordings of the individual spectra shown in Fig. 3. Normalization of these spectra is therefore arbitrary, such that quantitative inferences of relative signal intensities cannot immediately be made between different measurements, whereas the shapes of spectral features can still be readily 
compared. Relative intensities between different features of any single spectrum can of course also be compared.

Figure 2 shows the spectra recorded for the reference binary aqueous solutions of sodium decanoate, together with those recorded for ternary aqueous mixtures of $\mathrm{DecNa}$ with equimolar amounts of $\mathrm{NaCl}$ and $\left(\mathrm{NH}_{4}\right)_{2} \mathrm{SO}_{4}$ salts, respectively. The left panel (a) shows the more dilute solutions (approximately $10 \mathrm{mM}$ in each of the salts), and the right panel (b) shows the spectra measured for the more concentrated (approximately $25 \mathrm{mM}$ ) solutions. Comparing the Xray photoelectron spectra for binary DecNa to those for the ternary mixtures with $\mathrm{NaCl}$ and $\left(\mathrm{NH}_{4}\right)_{2} \mathrm{SO}_{4}$, it is immediately evident that no change occurs in the decanoate/decanoic acid $\mathrm{C} 1 \mathrm{~s}$ spectrum from the binary solution upon addition of equimolar amounts of $\mathrm{NaCl}$, in neither the more dilute, nor the more concentrated, solutions. On the other hand, at both concentrations, mixing with $\left(\mathrm{NH}_{4}\right)_{2} \mathrm{SO}_{4}$ leads to a pronounced change of the spectral shape in the $\mathrm{Dec}^{-} / \mathrm{DecH} \mathrm{C1s}$ region. The XPS spectra for the ternary DecNa- $\left(\mathrm{NH}_{4}\right)_{2} \mathrm{SO}_{4}$ solutions have been fitted with two Gaussian peaks using a least-squares method, where the line shapes of the peaks were assumed be symmetric Voigt profiles. The Lorentzian width, corresponding to the broadening due to the finite lifetime of the core hole, was fixed to $0.1 \mathrm{eV}$ (Campbell and Papp, 2001). The Gaussian widths, from instrumental contributions and inherent properties of the ionized species, such as variations in bonding patterns and vibrational excitations, were left as free parameters, but coupled so that they were the same for the individual peaks in all spectra. The energy positions were likewise free parameters, but also coupled so that the shifts between individual peaks were the same for all spectra. This yielded a robust fit, from which we have derived the fraction of the signal due to the decanoate ionic form from the integrated areas in the feature from the carboxylic carbon (see Table 2). The uncertainty in the values derived from the fits stems mostly from the assumptions made in the fitting procedure, and not from statistics, which makes it difficult to determine. A conservative estimate for the maximum error, based on our experience, is $10 \%$. In each of the fitted spectra, the carboxylic (protonated) signal appears to the left (at higher electron binding energies) of the carboxylate (deprotonated) signal. The positions of the $\mathrm{C} 1 \mathrm{~s}$ peaks clearly demonstrate that the change in spectral shape for the ternary $\left(\mathrm{NH}_{4}\right)_{2} \mathrm{SO}_{4}$ mixtures is in accordance with a large enhancement of the DecH feature, at more than $1 \mathrm{eV}$ higher binding energies, compared to $\mathrm{Dec}^{-}$.

In the more dilute ternary $\left(\mathrm{NH}_{4}\right)_{2} \mathrm{SO}_{4}$ solutions, the $\mathrm{Dec}^{-}$ signal itself is also enhanced, compared to the spectra for either the binary DecNa solutions or the ternary mixtures with $\mathrm{NaCl}$. A similar enhancement is not seen for the more concentrated solutions, which is therefore interpreted as an indication that the surfaces of the more concentrated binary solutions are already saturated with $\mathrm{Dec}^{-}$. This is consistent with two independent observations. First, the more highly concentrated solutions were observed to be close to the bulk solu- bility limit during sample preparation (see Supplement S1). Second, careful analysis of the intensity ratio between the C1s XPS signals of the carboxylate carbon and the aliphatic chain carbons yields $0.068 \pm 0.02$ and $0.060 \pm 0.03$ for the low and high concentration cases, respectively. These values both deviate from the stoichiometric ratio $1: 9=0.11$, and we interpret the under-stoichiometric intensity of the carboxylate carbon as due to a partial alignment of the molecules at the surface, consistent with the surface state above the dilute limit (where Traube's law hold), as described by e.g. Lunkenheimer and Hirte (1992); Hirte and Lunkenheimer (1996); Earnshaw et al. (1996). With the hydrofilic carboxylate carbon coordinated to water molecules in the liquid surface and the hydrophobic aliphatic chain sticking out of the surface, the carboxylate XPS signal would be attenuated relative to the signal from the chain carbons due to the longer path length of the photoelectrons from the carboxylate carbon. The reduction of the carboxylate/chain ratio from the lower to the higher concentration is thus consistent with the molecules standing more upright at the higher than at the lower concentrations, which is in turn consistent with the a denser packing of the molecules at the surface in the higher concentration cases. These two independent observations do thus support the interpretation that the decanoate overlayer is close to saturation in the high concentration cases, but not in the low concentration cases. Increased surface adsorption with increasing concentration is anticipated until surface saturation is reached, according to Gibbs adsorption theory (Gibbs et al., 1928). If the surface phase is not fully saturated in the more dilute solutions, more $\mathrm{Dec}^{-}$may consequently adsorb in response to changes in solution properties.

Notably, in neither the more dilute, nor the more concentrated, ternary $\left(\mathrm{NH}_{4}\right)_{2} \mathrm{SO}_{4}$ solutions does the $\mathrm{Dec}^{-}$feature decrease, compared to either the corresponding binary DecNa solutions or the ternary $\mathrm{NaCl}$ mixtures. The large enhancement of DecH in the surface phase therefore does not occur at the expense of the adsorbed $\mathrm{Dec}^{-}$and consequently more organic molecules in total (the sum of $\mathrm{Dec}^{-}$and $\mathrm{DecH}$ ) are present in the surface region of the ternary $\left(\mathrm{NH}_{4}\right)_{2} \mathrm{SO}_{4}$ solutions. Co-adsorption of two different surfactant species may be expected to affect surface properties, such as structure, reactivity, and aqueous surface tension.

To investigate whether the changes occurring in the solution surface upon addition of ammonium sulfate are caused specifically by $\mathrm{NH}_{4}^{+}, \mathrm{SO}_{4}^{2-}$, or the combination of these ions, we conducted experiments in which the combinations of cations and anions in the inorganic salts were interchanged. The corresponding XPS spectra measured for the ternary aqueous DecNa mixtures with $\mathrm{NH}_{4} \mathrm{Cl}$ and $\mathrm{Na}_{2} \mathrm{SO}_{4}$ are shown in Fig. 3. In each case, the relevant spectra from Fig. 2 are included again for comparison. The two upper panels in Fig. 3 show the spectra for ternary $\mathrm{Na}_{2} \mathrm{SO}_{4}$ mixtures, together with the ternary $\mathrm{NaCl}$ mixtures and the reference binary DecNa solutions, for the more dilute solutions (approximately $10 \mathrm{mM}$ of DecNa) in the left panel (a), and the 

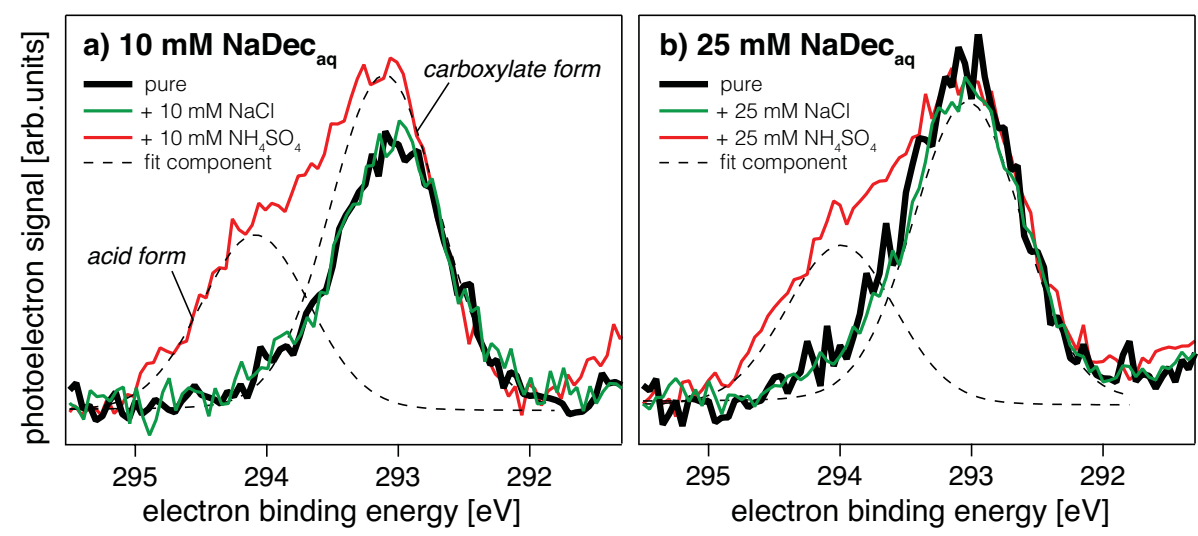

Fig. 2. X-ray photoelectron spectra for binary aqueous DecNa and ternary mixtures with $\mathrm{NaCl}$ and $\left(\mathrm{NH}_{4}\right)_{2} \mathrm{SO}_{4}$, showing the features in the region relevant for carboxylate and carboxylic acid $\mathrm{C} 1 \mathrm{~s}$ electron binding energies, respectively. Panel (a) shows spectra recorded for solutions of approximately $10 \mathrm{mM}$ in each solute, and panel (b) shows spectra for solutions of approximately $25 \mathrm{mM}$ in each solute. No change in the $\mathrm{Dec}^{-} / \mathrm{DecH}$ spectrum from the binary solution is seen upon mixing with $\mathrm{NaCl}$, at either concentration, whereas a strong carboxylic acid feature appears in both ternary mixtures with $\left(\mathrm{NH}_{4}\right)_{2} \mathrm{SO}_{4}$. At the lower concentrations in panel (a), the carboxylate signal is furthermore enhanced in the ternary $\left(\mathrm{NH}_{4}\right)_{2} \mathrm{SO}_{4}$ solutions.

more concentrated solutions (approximately $25 \mathrm{mM}$ DecNa) in the right panel (b). The lower panels in Fig. 3 show the measured spectra for ternary $\mathrm{NH}_{4} \mathrm{Cl}$ mixtures, together with ternary aqueous $\left(\mathrm{NH}_{4}\right)_{2} \mathrm{SO}_{4}$ mixtures and binary DecNa, for the dilute solutions in the left panel (c), and the concentrated solutions in the right panel (d).

Comparison of the spectral shapes for ternary mixtures with $\mathrm{Na}_{2} \mathrm{SO}_{4}, \mathrm{NH}_{4} \mathrm{Cl}, \mathrm{NaCl}$, and $\left(\mathrm{NH}_{4}\right)_{2} \mathrm{SO}_{4}$ and for the original spectra for binary aqueous DecNa in Fig. 3 clearly demonstrates that the additional DecH feature appears specifically upon addition of $\mathrm{NH}_{4}^{+}$ions. The shapes of the carboxylate/carboxylic acid $\mathrm{C} 1 \mathrm{~s}$ spectra measured for ternary $\mathrm{Na}_{2} \mathrm{SO}_{4}$ mixtures are fully consistent with those of binary aqueous DecNa and ternary $\mathrm{NaCl}$ mixtures at the same respective concentrations, whereas the spectral shapes of ternary $\mathrm{NH}_{4} \mathrm{Cl}$ mixtures look very similar to those of the corresponding ternary $\left(\mathrm{NH}_{4}\right)_{2} \mathrm{SO}_{4}$ mixtures, with the same strong enhancement of the surface DecH feature. Values of the decanoate surface ratio relative to the total carboxylate/carboxylic C1s peak $\left(Q\left(\mathrm{Dec}^{-}\right)=S\left(\mathrm{Dec}^{-}\right) /\left(S\left(\mathrm{Dec}^{-}\right)+\right.\right.$ $S(\mathrm{DecH}))$ ) obtained from the Gaussian fitting to the spectra are given for all solutions in Table 2. Overall, there is a $20-25 \%$ decrease in the contribution from the $\mathrm{Dec}^{-}$feature to the total carboxylate/carboxylic feature in ternary solutions with $\mathrm{NH}_{4}^{+}$ions, compared to binary DecNa solutions and ternary mixtures without ammonium. In Table 2, we also give the carboxylate/aliphatic chain ratios $(\mathrm{COO} / \mathrm{CH})$ for the investigated solutions. There is a clear decrease in the carboxylate signal going from the more dilute to the more concentrated solutions, indicating a more upright orientation of surfactant molecules in the more closely packed surfaces of the concentrated solutions. Variations immediately following the corresponding decanoate surface ratios in accordance with the inferred total increase in adsorbed de- canoate + decanoic acid are however not seen. Likely, the $\mathrm{COO} / \mathrm{CH}$ ratios are not sensitive enough to capture the variation in total adsorbed organic between experiments with similar concentrations. There is more than a factor of two difference in concentration between the more dilute and the more concentrated solutions, whereas the $Q\left(\mathrm{Dec}^{-}\right)$ratios indicate an increase in total adsorbed decanoate + decanoic acid of about $25 \%$ in the ternary mixtures with ammonium ions (e.g. for $10 \mathrm{mM}$ DecNa vs. $10 \mathrm{mM} \mathrm{DecNa}+\left(\mathrm{NH}_{4}\right)_{2} \mathrm{SO}_{4}$ : $1-0.679 / 0.908=0.252$ ).

In an aqueous solution of either $\mathrm{Dec}^{-}$or $\mathrm{DecH}$, there will always be some of the corresponding acid or base present, due to the protonation/protolysis equilibrium given in Eq. (2). According to the acid strength of decanoic acid, as expressed by the acid constant $\mathrm{p} K_{\mathrm{a}}(\mathrm{DecH})=4.9$ (Stahl and Wermuth, 2002), the vast majority of the $\mathrm{Dec}^{-} / \mathrm{DecH}$ system will be on the basic $\left(\mathrm{Dec}^{-}\right)$form in a dilute solution of DecNa close to neutral $\mathrm{pH}(\approx 7)$. It is therefore not surprising that very little DecH is present in the binary DecNa solution surfaces. At concentrations below the respective solubility limits (or possibly the critical micelle concentrations), either of the corresponding $\mathrm{Dec}^{-} / \mathrm{DecH}$ forms will be enhanced in the surface phase, if the corresponding activities ( $a=\gamma_{\mathrm{c}} c$, where $\gamma_{\mathrm{c}}$ is the activity coefficient according to the concentration scale $c$ in question) are increased (Gibbs et al., 1928). An increase in activity may thus result from increased bulk-phase concentrations, or from non-ideal interactions increasing organic activity coefficients. If more decanoic acid is formed in the solution, enhanced surface abundances can therefore subsequently be expected. Decanoic acid is intrinsically more surface active than the corresponding decanoate ions (Wen et al., 2000; Fainerman et al., 2002; Lide, 2004), which would further contribute to the effect. When the bulk solubility of a solute is decreased due to the addition of salts 
to the solution, it is often referred to as "salting-out". Disregarding any specific changes in surface adsorption properties arising directly as a consequence of the change in mixing state, a decrease in bulk-phase solubility of a solute may be expected to increase the activity corresponding to a given concentration of this solute (below the solubility limit or the $\mathrm{cmc}$ ) and may in turn also lead to enhanced surface adsorption. For an ionic solute, such as DecNa, this can formally occur, either from the additional salt increasing the sodium and/or decanoate ionic activities (Fainerman et al., 2002), by increasing the overall solution ionic strength ( $I$, see Eq. 3 below), or from the common sodium counter cations decreasing the specific contribution of the decanoate anion concentration to the DecNa solubility product.

We will now proceed to critically discuss these and other possible explanations for the experimental observations.

\subsection{Ionic strength and salting-out}

The ionic strength (on a molar concentration scale) of a solution is defined as

$$
I=0.5 \sum_{i=1}^{n} c_{i}\left(z_{i}\right)^{2}
$$

where $c_{i}$ is the molar concentration (in $[\mathrm{M}]=\left[\mathrm{moll}^{-1}\right]$ ) of ion $i$, calculated from the concentration of undissociated salt and the number of ions per formula unit, by assuming complete dissociation of each salt, $z_{i}$ is the charge number of that ion, and the sum is taken over all ions $(n)$ within the solution considered. The ionic strength can be regarded as a crude approximation of the total activity of dissolved ionic solutes, and is as such an indicator of the overall strength of non-ideal solute-solute interactions in solution. However, the concept is based on considerations strictly applicable to small inorganic ions and for bulky organic ions, such as $\mathrm{Dec}^{-}$, with both polar and non-polar moieties, further (and non-trivial) considerations are needed to determine ionic activities more accurately (Robinson and Stokes, 2002, e.g.). It must furthermore be noted that $\mathrm{DecH}$ is also expected to influence and be affected by solution non-ideality, but as a molecular solute does not enter directly into the simplified framework provided by considerations of ionic strength.

Calculated ionic strengths for the investigated solutions are listed in Table 2, first by including the total amount of ions present, inorganic as well as decanoate ions $\left(I_{\text {tot }}\right)$ and second by only considering inorganic ions $\left(I_{\text {inorg }}\right)-$ which however still originate from dissociation of both DecNa and inorganic salts. Solution ionic strength is enhanced relatively more in $\left(\mathrm{NH}_{4}\right)_{2} \mathrm{SO}_{4}$ mixtures, compared to other ternary solutions of equimolar inorganic concentrations, due to the greater number of ions per formula unit of undissociated salt and the higher ionic charge of the sulfate anions. From these considerations, it is now clear that the strong surface DecH signal is not simply caused by salting-out from increased ionic strength in ternary solutions. Increasing $I_{\text {inorg }}$ in the more concentrated solutions from $28.6 \mathrm{mM}$ in binary aqueous DecNa to $57.2 \mathrm{mM}$ and $98.0 \mathrm{mM}$ in ternary $\mathrm{NaCl}$ and $\mathrm{Na}_{2} \mathrm{SO}_{4}$ mixtures, and in the more dilute solutions from $9.8 \mathrm{mM}$ in binary aqueous DecNa to $19.8 \mathrm{mM}$ and $40.0 \mathrm{mM}$ in ternary $\mathrm{NaCl}$ and $\mathrm{Na}_{2} \mathrm{SO}_{4}$ mixtures, makes virtually no difference for the shape of the photoelectron spectra and notably does not lead to any increased intensity of the weak DecH feature.

The decanoate surface ratios $\left(Q\left(\mathrm{Dec}^{-}\right)\right.$, see Table 2$)$ indicate a slight salting-out effect on $\mathrm{Dec}^{-}$anions from common $\mathrm{Na}^{+}$counter cations upon mixing with either $\mathrm{NaCl}$ or $\mathrm{Na}_{2} \mathrm{SO}_{4}$. The effect appears slightly stronger in the more concentrated solutions of higher ionic strength, but is weak, at best, in each of the present experiments. Looking at the spectra in Fig. 2, the shape and intensity of the $\mathrm{Dec}^{-}$feature is virtually unaffected by the addition of $\mathrm{NaCl}$ doubling the concentration of $\mathrm{Na}^{+}$, and Fig. 3 furthermore shows how the spectral shape is invariant between each of the binary DecNa and ternary $\mathrm{NaCl}$ and $\mathrm{Na}_{2} \mathrm{SO}_{4}$ solutions. This is somewhat surprising, since $\mathrm{Na}^{+}$might be expected to have a significant salting-out effect on DecNa via the solubility product, even in the absence of unfavorable non-ideal $\left(\gamma_{\mathrm{c}}>1\right)$ solute interactions. Poorly constrained salting-out phenomena by common ions have occasionally been invoked to explain experimental observations regarding aqueous aerosol systems. Such mechanisms may still be important in aqueous mixtures with different organic-inorganic solute mixing ratios and at different concentration ranges. Furthermore, the enhanced $\mathrm{Dec}^{-}$surface abundance seen in Fig. 2 does indicate a salting-out effect of decanoate anions upon mixing with sulfate ions in the more dilute ternary $\left(\mathrm{NH}_{4}\right)_{2} \mathrm{SO}_{4}$ solutions, which may stem from the increased ionic strength in these solutions. The inorganic ionic strength is more than doubled, going from the ternary $\mathrm{NaCl}$ to $\left(\mathrm{NH}_{4}\right)_{2} \mathrm{SO}_{4}$ mixtures. It is entirely conceivable that this could have an even greater effect on $\mathrm{Dec}^{-}$activities than common $\mathrm{Na}^{+}$ions in the solutions investigated. Salting-out of the organic decanoate anions in solutions of higher ionic strength would in turn be evidence of non-ideal solute-solute interactions affecting aqueous solution properties, even at these rather low concentrations. This is particularly interesting in an atmospheric context, because non-ideal interactions are often assumed to be negligible for such aqueous systems as activating cloud droplets. Unfortunately, the effect cannot be verified for the ternary $\mathrm{Na}_{2} \mathrm{SO}_{4}$ solutions, owing to the lack of quantitative comparison of the XPS spectral intensities in these measurements.

\subsection{Equilibrium considerations}

At the core of making the XPS feasible for aqueous systems is the continual renewal of the sample using the liquid jet (Winter and Faubel, 2006). This means that a new surface is formed continuously, within a time frame of the order of $10^{-4} \mathrm{~s}$ from leaving the nozzle to measurement. It is now generally accepted that this time scale is sufficiently 


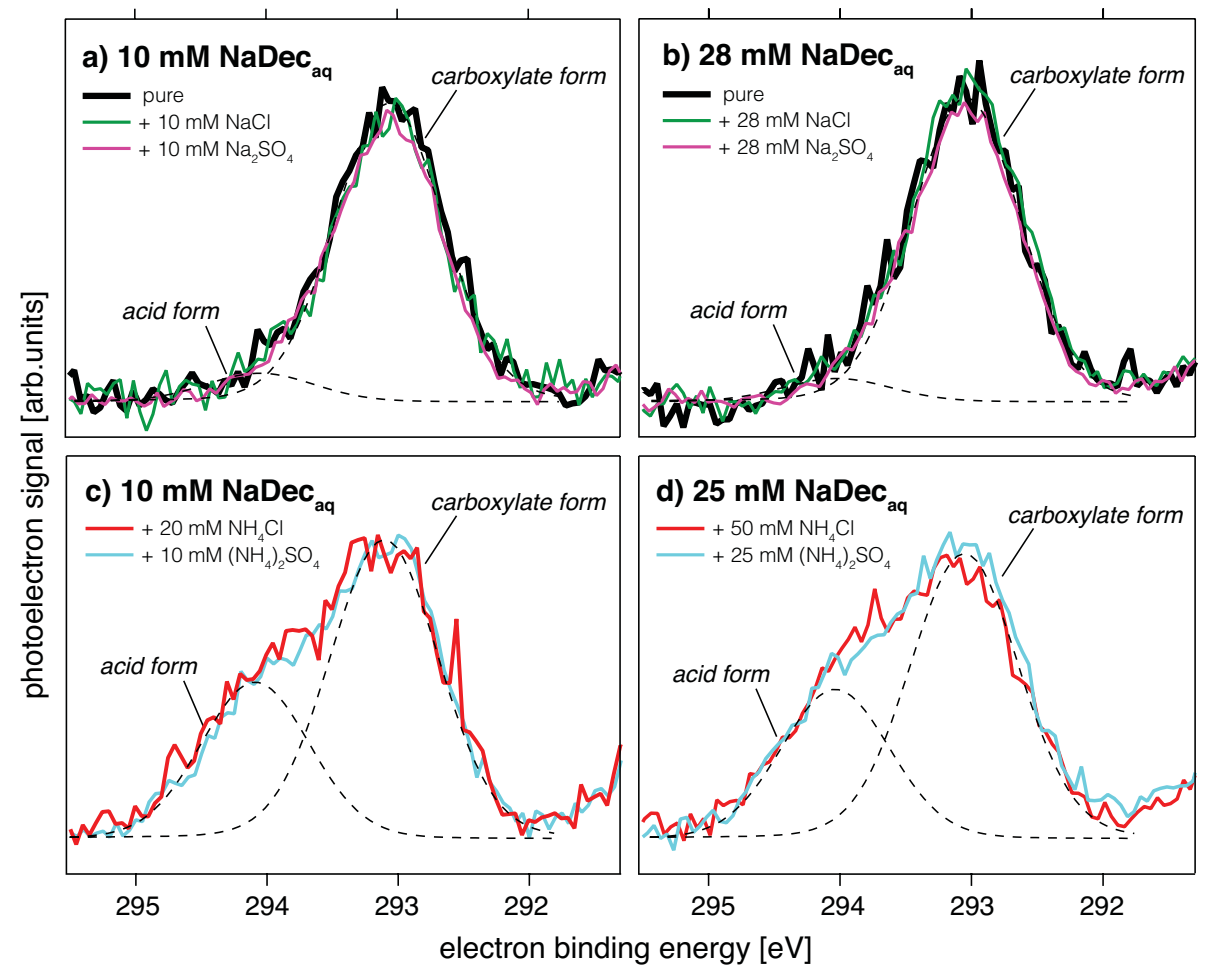

Fig. 3. X-ray photoelectron spectra recorded in the electron binding energy region relevant for carboxylate and carboxylic acid $\mathrm{C} 1 \mathrm{~s}$ for ternary aqueous DecNa mixtures with $\mathrm{NH}_{4} \mathrm{Cl}$ and $\mathrm{Na}_{2} \mathrm{SO}_{4}$, shown together with the relevant spectra for binary aqueous DecNa and the ternary mixtures with $\mathrm{NaCl}$ and $\left(\mathrm{NH}_{4}\right)_{2} \mathrm{SO}_{4}$ from Fig. 2. Spectra are shown for ternary $\mathrm{Na}_{2} \mathrm{SO}_{4}$ mixtures, together with the ternary $\mathrm{NaCl}$ mixtures and the reference binary DecNa solutions, for solutions of $10 \mathrm{mM}$ DecNa in (a), and for $25 \mathrm{mM}$ DecNa in (b). Spectra for ternary $\mathrm{NH}_{4} \mathrm{Cl}$ mixtures, together with the ternary $\left(\mathrm{NH}_{4}\right)_{2} \mathrm{SO}_{4}$ mixtures and binary DecNa solutions, are shown for $10 \mathrm{mM}$ solutions in $(\mathbf{c})$, and for $25 \mathrm{mM}$ solutions in (d). The strong enhancement of the carboxylic acid feature clearly occurs upon mixing with inorganic salts comprising $\mathrm{NH}_{4}^{+}$.

long for the surfaces of solutions of inorganic ions and small molecules to equilibrate (Winter and Faubel, 2006). Longchain fatty acids and their corresponding anionic bases, such as the $\mathrm{Dec}^{-} / \mathrm{DecH}$ pair investigated here, have however in some cases been observed to display very long equilibration time scales in dynamic surface tension measurements. These long equilibration times are nevertheless thought to be related to structural rearrangements occurring within the surface phase, rather than arising from slow molecular diffusion from the bulk to the surface, which is considered to be much faster (Prisle et al., 2008, and references therein). Still, we cannot a priori exclude that the aqueous surfaces probed in the liquid-jet experiments in this work have not equilibrated in terms of the extent of surface adsorption of either surfactant species. Naturally, this could affect the relative $\mathrm{Dec}^{-} / \mathrm{DecH}$ surface abundances inferred from the Gaussian peak heights fitted to the measured XPS spectra in Figs. 2 and 3 .

Along similar lines of reasoning, insufficient equilibration times from generation of the liquid jet and until detection of the emitted photoelectron signal could explain our failure to observe any significant $\mathrm{Dec}^{-}$salting-out upon mixing with $\mathrm{Na}^{+}$, in that any potential enhanced surface adsorption of the surfactant is not captured within the time frame of the measurements. However, as noted above for Fig. 2, the ternary $\left(\mathrm{NH}_{4}\right)_{2} \mathrm{SO}_{4}$ mixtures do in fact show enhanced surface adsorption of DecH, and in the more dilute case also of $\mathrm{Dec}^{-}$, compared to the binary DecNa solutions. The identities of the adsorbing surfactant species ( $\mathrm{Dec}^{-}$and $\mathrm{DecH}$ ) involved in these different experiments are the same, as are the concentrations, diffusion distances and experimental time scales. We do not expect the diffusion constants for $\mathrm{Dec}^{-}$and DecH to be significantly different with respect to the present measurements (i.e. for the measurement time scales in question, in dilute solutions, and in absence of electric fields). If enhanced adsorption of $\mathrm{Dec}^{-}$in ternary mixtures with $\mathrm{Na}^{+}$salts occurred, we should therefore observe an enhanced $\mathrm{Dec}^{-}$feature in the recorded spectra, similar to the enhancements seen for both $\mathrm{Dec}^{-}$and DecH in the $\left(\mathrm{NH}_{4}\right)_{2} \mathrm{SO}_{4}$ solutions. We therefore conclude that for the present case, just as for solutions of inorganic ions and small molecules, absence of enhanced $\mathrm{Dec}^{-}$surface abundances is not caused by insufficient equilibration. By the same argument, we also do not consider the absence of a significant DecH signal for 
solutions without $\mathrm{NH}_{4}^{+}$to be an artefact resulting from the limited time scale of the experiments.

\subsection{Surface vs. bulk-phase protonation?}

The decanoic acid and the ammonium cation may act as Brønsted acids (proton donors) in aqueous solution, and the decanoate and sulfate anions as Brønsted bases (proton acceptors), whereas the sodium and chloride ions have practically no acid/base properties in this respect. The results presented in Fig. 2 above clearly demonstrate that mixing with $\mathrm{NH}_{4}^{+}$, and not increased solution ionic strength, causes the greatly enhanced DecH feature observed for the ternary $\left(\mathrm{NH}_{4}\right)_{2} \mathrm{SO}_{4}$ and $\mathrm{NH}_{4} \mathrm{Cl}$ mixtures. We therefore further conclude that the strong enhancement of DecH in the solution surface is due to acid-base chemistry, where a proton from $\mathrm{NH}_{4}^{+}$is (directly or indirectly) transferred to the $\mathrm{Dec}^{-}$carboxylate group, forming the corresponding carboxylic acid according to the net reaction:

$\mathrm{NH}_{4}^{+}{ }_{(\mathrm{aq})}+\mathrm{Dec}^{-}{ }_{(\mathrm{aq})} \leftrightharpoons \mathrm{NH}_{3(\mathrm{aq})}+\operatorname{DecH}_{(\mathrm{aq})}$

To test this hypothesis, we performed additional XPS measurements focusing particularly on nitrogen. In Fig. 4, the photoelectron spectrum in the N1s region for a ternary 10 $\mathrm{mM}$ sodium decanoate and $20 \mathrm{mM}$ ammonium chloride solution is shown. The signal is very weak, in accordance with the low concentration of ammonium chloride, and its nonsurfactant character. In addition to the signal from aqueous ammonium ions at $406.8 \mathrm{eV}$, a shoulder at $405.5 \mathrm{eV}$ can be seen, which matches the binding energy of $405.52 \mathrm{eV}$ for ammonia in the gas phase (Mills et al., 1976). The ammonium binding energy is close to that of the ammonium group in the cationic form of glycine, $406.9 \mathrm{eV}$ (Ottosson et al., 2011a). The spectrum has been energy calibrated relative to the HOMO in the valance band of liquid water at $11.16 \mathrm{eV}$ (Winter et al., 2004) and while gas-phase and liquid-phase energy scales generally cannot be immediately compared, in this case the corresponding gas-phase line was found at the literature value of $12.6 \mathrm{eV}$ (Kimura, 1981).

As mentioned in Sect. 3 above, based on the overall dilute nature of the solutions and the weak acid-base character of $\mathrm{DecH}$ and $\mathrm{Dec}^{-}$(as well as the inorganic solutes), we expect the investigated samples to be close to neutral $\mathrm{pH}$ and the vast majority of the $\mathrm{DecH} / \mathrm{Dec}^{-}$pair to be on the ionic form. If the observed significant enhancement of the DecH feature was reflecting corresponding changes in bulk chemistry, it should be accompagnied by a large (and unexpected) change in solution $\mathrm{pH}$. As a check, we therefore measured the $\mathrm{pH}$ in the remainders of the solution samples after each liquidjet experiment. When possible, we made parallel determinations using two different $\mathrm{pH}$ instruments (a portable Thermo Scientific meter and a Hanna/Mettler Toledo meter). In a few cases, there was unfortunately not enough sample available for the $\mathrm{pH}$ measurements to be performed. Measured $\mathrm{pH}$ values for the investigated solutions are listed in Table 2.
None of the solutions, neither the more concentrated, nor the more dilute, had a $\mathrm{pH}$ significantly different from neutral, exactly as expected. The Thermo Scientific meter consistently gave slightly higher readings than the Hanna/Mettler Toledo, and both meters consistently showed a slightly lower $\mathrm{pH}$ for the more dilute $(10 \mathrm{mM})$ than the more concentrated $(25 \mathrm{mM})$ solutions. From the variation in the measured $\mathrm{pH}$ values, the accuracy of these measurements is expected to be at least within \pm 0.05 . We are therefore convinced that the bulk $\mathrm{pH}$ is in each case sufficiently far from the decanoic acid $\mathrm{p} K_{\mathrm{a}}(=4.9)$ to strongly indicate that the significant enhancement of the DecH feature in the XPS spectra must be a purely surface-specific effect. To further support this interpretation of surface-specific chemistry, we also performed supporting bulk- ${ }^{1} \mathrm{NMR}$ measurements. The individual $\mathrm{DecH}$ and $\mathrm{Dec}^{-}$forms are clearly distinguishable in the proton NMR spectra, shown in the Supplement (S3). For solutions equivalent to those investigated in the XPS experiments, the $\mathrm{H}^{1} \mathrm{NMR}$ spectra show a bulk-phase signal which is nearly identical to that of pure DecNa in water, thus essentially devoid of any signal from the DecH form, and in complete agreement with the measured $\mathrm{pH}$ values. This excludes a significant change in solution bulk-phase composition as $\mathrm{NH}_{4}^{+}$donate protons to $\mathrm{Dec}^{-}$, and thus confirms that what we see in the XPS measurements is indeed a surface-specific effect.

Considering the much enhanced surface concentrations upon surfactant adsorption and (likely) counterion coadsorption to preserve electro-neutrality of the surface phase, increased protonation of $\mathrm{Dec}^{-}$according to a Le Chatelier shift of the equilibrium given in Eq. (4) is not surprising. The notion of a surface specific acid-base reaction is highly interesting in the context of atmospheric aerosols, as $\mathrm{pH}$ is a crucial and very sensitive property of atmospheric aqueous systems. A distinction between bulk and surface-phase reactivity is expected to influence atmospheric reaction pathways, time scales, and processing involving aqueous aerosol.

\subsection{Relative surface enrichment}

We performed additional XPS measurements to estimate the surface adsorption of surfactant according to a simple model (see Supplement S4). This way we determine the relative surface enrichment factor for decanoate in a $10 \mathrm{mM}$ binary solution to be in the range of $20-190$, with a most probable value of $K=63$. This means that in the aqueous surface the average distance between nearest molecular neighbours of decanoate, i.e. the decanoate concentration, is 63 times higher than in the solution bulk. Estimating the decanoate molecular length as the sum of the aliphatic chain and the $\mathrm{C}=\mathrm{O}$ bond lengths (Roszak et al., 2005; Liang, 2008), we get $L_{\text {Dec }^{-}}=9.2 \AA$, and if we furthermore assume the molecules to be tilted at a $45^{\circ}$ angle to the surface plane, the thickness of the surface layer is then estimated as $D=4.8 \AA$. With the surface enrichment factor of 63 , this gives a surface 

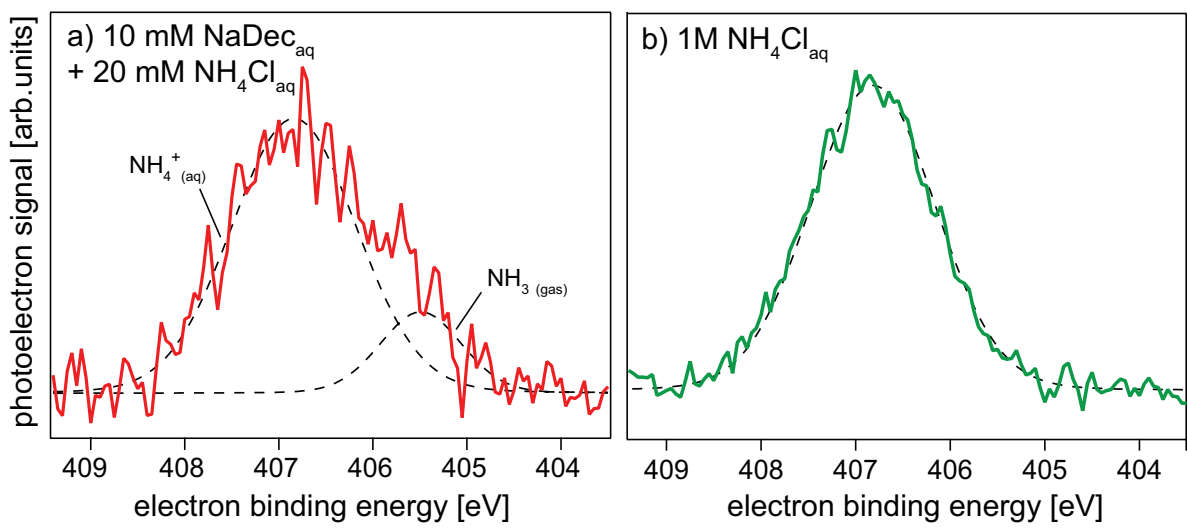

Fig. 4. N1s XPS spectra for (a) an aqueous solution of $10 \mathrm{mM}$ sodium decanoate and $20 \mathrm{mM}$ ammonium chloride and, for comparison, for (b) $1 \mathrm{M}$ aqueous ammonium chloride. The spectrum for the ternary solution shows signals from both ammonium ions in the solution and ammonia molecules in the gas phase, whereas no gas-phase signal is seen in case of the binary salt solution.

Table 2. Properties of measured solutions: Molar concentrations $(c[\mathrm{mM}])$ of organic and inorganic salts, respectively. Decanoate surface ratio $Q\left(\mathrm{Dec}^{-}\right)=S\left(\mathrm{Dec}^{-}\right) /\left(S\left(\mathrm{Dec}^{-}\right)+S(\mathrm{DecH})\right)$. Total ionic strength $\left(I_{\text {tot }}[\mathrm{mM}]\right)$ and ionic strength from inorganic ions $\left(I_{\text {inorg }}[\mathrm{mM}]\right)$. Measured $\mathrm{pH}$, with two different instruments: Hanna/Mettler Toledo meter ( $\mathrm{pH} 1)$ and a portable Thermo Scientific meter (pH2).

\begin{tabular}{lcccccccc}
\hline Experiment & organic $[\mathrm{mM}]$ & inorganic $[\mathrm{mM}]$ & $Q\left(\mathrm{Dec}^{-}\right)$ & $\mathrm{COO} / \mathrm{CH}$ & $I_{\text {tot }}[\mathrm{mM}]$ & $I_{\text {inorg }}[\mathrm{mM}]$ & $\mathrm{pH} 1$ & $\mathrm{pH} 2$ \\
\hline DecNa & 9.8 & - & 0.908 & 0.074 & 9.8 & 9.8 & - & - \\
$\mathrm{DecNa}+\mathrm{NaCl}$ & 9.8 & 10.0 & 0.939 & 0.066 & 19.8 & 14.9 & 7.09 & - \\
$\mathrm{DecNa}+\mathrm{Na}_{2} \mathrm{SO}_{4}$ & 10.0 & 10.0 & 0.933 & 0.071 & 40.0 & 35.0 & 6.86 & 6.94 \\
$\mathrm{DecNa}+\left(\mathrm{NH}_{4}\right)_{2} \mathrm{SO}_{4}$ & 9.8 & 10.1 & 0.679 & 0.067 & 40.1 & 35.2 & 7.06 & - \\
$\mathrm{DecNa}+\mathrm{NH}_{4} \mathrm{Cl}$ & 10.6 & 23.3 & 0.751 & 0.074 & 33.9 & 28.6 & 6.79 & 6.86 \\
\hline $\mathrm{DecNa}$ & 28.6 & - & 0.906 & 0.065 & 28.6 & 28.6 & 7.07 & - \\
DecNa$+\mathrm{NaCl}_{\mathrm{NecNa}} \mathrm{Na}_{2} \mathrm{SO}_{4}$ & 28.6 & 28.6 & 0.931 & 0.066 & 57.2 & 43.0 & 6.92 & - \\
DecNa$+\left(\mathrm{NH}_{4}\right)_{2} \mathrm{SO}_{4}$ & 24.5 & 24.5 & 0.963 & 0.060 & 98.0 & 85.7 & 7.08 & 7.14 \\
$\mathrm{DecNa}+\mathrm{NH}_{4} \mathrm{Cl}$ & 28.6 & 27.9 & 0.667 & 0.060 & 112.2 & 97.9 & 6.83 & - \\
\hline
\end{tabular}

adsorption of $\Gamma_{\mathrm{XPS}}=3.0 \times 10^{-7} \mathrm{~mol} \mathrm{~m}^{-2}$, and for the range of enrichment factors between 20 and 190, the corresponding surface adsorption range is $9.7 \times 10^{-8}$ to $9.2 \times 10^{-7} \mathrm{~mol} \mathrm{~m}^{-2}$.

Fainerman et al. (2002) give fitted Frumkin model parameters of partial molar surface area $\left(\omega=2.6 \times 10^{5} \mathrm{~m}^{2} \mathrm{~mol}^{-1}\right)$ and adsorption constant $\left(b=18.3 \mathrm{~L} \mathrm{~mol}^{-1}\right)$ for the measured surface tension isotherm for sodium decanoate in $0.1 \mathrm{M} \mathrm{NaOH}$. Using these values and for simplicity assuming solution ideality (intermolecular interaction constant $a=0$ and mean ionic product of $c^{*}=0.10$ ), we this way estimate the surface adsorption of decanoate to be $\Gamma_{\mathrm{DecNa}+\mathrm{NaOH}}=2.5 \times 10^{-6} \mathrm{~mol} \mathrm{~m}^{-2}$ in a $10 \mathrm{mM}$ solution, in good agreement with the upper end of the estimated range of surface enrichment factors from our XPS measurements. With values of the pure water surface tension of $\sigma_{w}^{283 \mathrm{~K}}=74.22 \mathrm{mNm}^{-1}$ and $\sigma_{w}^{298 \mathrm{~K}}=71.96 \mathrm{mNm}^{-1}$ at temperatures of 283 and $298 \mathrm{~K}$, respectively, the adsorption value $2.5 \times 10^{-6} \mathrm{~mol} \mathrm{~m}^{-2}$ gives corresponding aqueous decanoate surface tensions of $\sigma_{\mathrm{DecNa}+\mathrm{NaOH}}^{283 \mathrm{~K}}=55.4 \mathrm{mN} \mathrm{m}^{-1}$ and $\sigma_{\mathrm{DecNa}+\mathrm{NaOH}}^{298 \mathrm{~K}}=52.1 \mathrm{mNm}^{-1}$ from the Frumkin model with the approximations made here. To our knowledge, experimental surface tension-concentration isotherms for ternary aqueous mixtures of sodium decanoate and either sodium chloride or ammonium sulfate are not reported in the literature. These have however been measured by N. L. Prisle and co-workers (unpublished data) and specifically for a $10 \mathrm{mM} \mathrm{50:50 \%} \mathrm{mixture} \mathrm{by} \mathrm{mass} \mathrm{of} \mathrm{sodium}$ decanoate and ammonium sulfate at $298 \mathrm{~K}$, a surface tension of $\sigma_{\mathrm{DecNa}}+\left(\mathrm{NH}_{4}\right)_{2} \mathrm{SO}_{4} \approx 35 \mathrm{mNm}^{-1}$ is found. During the same measurements, the surface tension of binary aqueous sodium decanoate was determined as $\sigma_{\mathrm{DecNa}} \approx 44 \mathrm{mNm}^{-1}$, in reasonable agreement with the value estimated from the Frumkin model-derived surface adsorption, considering that the binary surface tension isotherm is in the latter case measured for aqueous sodium decanoate with no addition of $\mathrm{NaOH}$ to suppress protonation. 
Looking at the changes in relative surface composition given by the decanoate surface ratios $Q\left(\mathrm{Dec}^{-}\right)$in Table 2, the values for $10 \mathrm{mM}$ binary sodium decanoate and ternary sodium decanoate $+\left(\mathrm{NH}_{4}\right)_{2} \mathrm{SO}_{4}$ solutions are 0.908 and 0.679 , respectively. Assuming that the enhancement of the DecH signal in the surface of the ternary ammonium sulfate solutions indeed does not occur at the expense of adsorbed surface $\mathrm{Dec}^{-}$, this corresponds to an increase of $(1-0.679 / 0.908)=0.252$ of the total organic adsorbed in the surface. If we, for the lack of a better approach, equate the decanoic acid in the surface to decanoate and assume this $25 \%$ increase to be in the decanoate surface adsorption, this would translate into a decrease in solution surface tension from $52.1 \mathrm{mNm}^{-1}$ to $40.4 \mathrm{mN} \mathrm{m}^{-1}$ at $298 \mathrm{~K}$, a difference of $11.7 \mathrm{mN} \mathrm{m}^{-1}$ or $22 \%$, according to the simplified Frumkin isotherm. This estimate likely represents a lower bound for the effect on surface tension of enhanced decanoic acid surface abundance, since it is being equated to the effect of the weaker surfactant decanoate and furthermore any potential synergetic effects of decanoate/decanoic acid co-adsorption are not considered. The estimated change is nevertheless in good agreement with the measured decrease in surface tension of $9 \mathrm{mN} \mathrm{m}^{-1}$, albeit from $44 \mathrm{mN} \mathrm{m}^{-1}$ to $35 \mathrm{mN} \mathrm{m}^{-1}$, between binary sodium decanoate and ternary sodium decanoate + ammonium sulfate solutions. As a minor note, these solutions contain somewhat more ammonium sulfate ( $50 \%$ by mass) than the solutions studied by XPS + liquid jet here, which are equimolar mixtures of DecNa and $\left(\mathrm{NH}_{4}\right)_{2} \mathrm{SO}_{4}$. The effect of $\left(\mathrm{NH}_{4}\right)_{2} \mathrm{SO}_{4}$ on surface tension reduction may therefore be slightly smaller in the present XPS experiments, compared to the mentioned surface tension measurements.

For the $25 \mathrm{mM}$ solutions, we do not have equivalent XPS measurements from which to estimate the surface enrichment factor for decanoate. However, by following analogous arguments as for the $10 \mathrm{mM}$ case, we estimate the surface adsorption from the Frumkin model with the parameters of Fainerman et al. (2002) and a mean ionic product of $c^{*}=0.17$ as $\Gamma_{\mathrm{DecNa}+\mathrm{NaOH}}=2.9 \times 10^{-6} \mathrm{~mol} \mathrm{~m}^{-2}$. This yields a surface tension of $\sigma_{\mathrm{DecNa}+\mathrm{NaOH}}^{298 \mathrm{~K}}=45.4 \mathrm{mN} \mathrm{m}^{-1}$. Using the appropriate decanoate surface ratios from Table 2, we estimate an increase in surface adsorption of $(1-0.667 / 0.906)=0.264$ for ternary aqueous mixtures with ammonium sulfate. Such an increase in decanoate surface adsorption would then reduce the surface tension to $\sigma_{\mathrm{DecNa}+\mathrm{NaOH}}^{298 \mathrm{~K}}=14.6 \mathrm{mNm}^{-1}$, a dramatic drop of $30.8 \mathrm{mN} \mathrm{m}^{-1}$ or $68 \%$. The lower surface tension value is however almost certainly unrealistically low, as the surface tension isotherm has been extrapolated beyond the measured concentration range used by Fainerman et al. (2002) and the value is significantly below the measured surface tension range by Campbell and Lakshminarayanan (1965), even for much higher aqueous concentrations of binary sodium decanoate. The isotherms measured by N. L. Prisle and co-workers (unpublished data) give sur- face tension values of $\sigma_{\mathrm{DecNa}} \approx 37 \mathrm{mNm}^{-1}$ for binary aque-

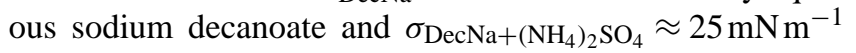

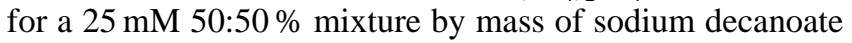
and ammonium sulfate. These values are much more realistic, being constrained by actual measurements, even if the ternary solutions are very likely gracing the $\mathrm{cmc}$, and the difference still represents a significant $34 \%$ decrease in aqueous surface tension upon mixing with $\left(\mathrm{NH}_{4}\right)_{2} \mathrm{SO}_{4}$.

\subsection{Atmospheric relevance and implications}

We here studied dilute 10 and $25 \mathrm{mM}$ aqueous solutions of the organic surfactant sodium decanoate, as pure solute and in mixtures with different inorganic salts. The investigated concentrations are constrained by the requirements of the XPS + liquid jet technique used for the experiments, as well as intrinsic aqueous solubility properties of the solutes involved. We notice that our sample systems give a good representation of the concentration range spanning the surface tension transition region between the pure water and $\mathrm{cmc}$ values. Prisle et al. (2008) calculate that spherical aerosol particles comprising pure sodium decanoate and with diameters of 40 and $100 \mathrm{~nm}$ grow by water uptake into droplet sizes of about 50 and $300 \mathrm{~nm}$, respectively, at ambient water saturation $(\mathrm{RH}=100 \%)$ and subsequently reach the point of cloud activation in the supersaturated regime at droplet sizes in the ranges of 140-200 and 500-700 nm, depending on different underlying model assumptions. The thermodynamic model in each case assumes volume additivity of the components upon forming the aqueous droplet phase. With a molar mass of $M_{\mathrm{DecNa}}=194.25 \mathrm{~g} \mathrm{~mol}^{-1}$ (see Table 1) and furthermore assuming unit mass density for sodium decanoate $\left(\rho_{\mathrm{DecNa}}=\right.$ $1 \mathrm{~g} \mathrm{~cm}^{-3}$ ), these droplet sizes correspond to aqueous solutions with concentrations of $2.66 \mathrm{M}$ and $120-41.2 \mathrm{mM}$ for the original $40 \mathrm{~nm}$ particle, and to $191 \mathrm{mM}$ and $41.2-15.0 \mathrm{mM}$ for the $100 \mathrm{~nm}$ particle, respectively. If half of the initial aerosol mass was instead comprised by ammonium sulfate, with a mass density of $\rho_{\left(\mathrm{NH}_{4}\right)_{2} \mathrm{SO}_{4}}=1.769 \mathrm{~g} \mathrm{~cm}^{-3}$ (Lide, 2004) and a molar mass of $M_{\left(\mathrm{NH}_{4}\right)_{2} \mathrm{SO}_{4}=132.14 \mathrm{~g} \mathrm{~mol}^{-1}}$ (see Table 1), aqueous droplets of the same sizes formed on 40 and $100 \mathrm{~nm}$ dry particles would instead correspond to solutions with DecNa and $\left(\mathrm{NH}_{4}\right)_{2} \mathrm{SO}_{4}$ concentrations of $1.68 \mathrm{M}$ and $76.7-26.3 \mathrm{mM}$ and $2.48 \mathrm{M}$ and $113-38.7 \mathrm{mM}$ for the $40 \mathrm{~nm}$ particles and $122 \mathrm{mM}$ and $23.3-9.6 \mathrm{mM}$ and $179 \mathrm{mM}$ and $38.7-14.1 \mathrm{mM}$ for the $100 \mathrm{~nm}$ particles. Here, we have further assumed a volume weighted effective particle density for the mixed particles of

$\rho_{\mathrm{eff}}=\left(\frac{0.5}{\rho_{\mathrm{DecNa}}}+\frac{0.5}{\rho_{\left(\mathrm{NH}_{4}\right)_{2} \mathrm{SO}_{4}}}\right)^{-1}=1.278 \mathrm{~g} \mathrm{~cm}^{-3}$

Several of these aqueous droplets are above the bulk solubility (or cmc) limit for DecNa. However, submicrometer droplets have very large surface areas relative to their bulk volumes and, contrary to macroscopic solutions, bulkphase concentrations may thus be significantly depleted in 
dissolved surfactant, due to surface adsorption. Prisle et al. (2010b) estimate that for a total concentration of $40 \mathrm{mM}$, approximately $25 \%$ of all dissolved DecNa is adsorbed at the surface of a $1 \mu \mathrm{m}$ droplet, with the fraction increasing rapidly as a function of decreasing droplet size. For the submicron droplets used as illustration above, the bulk phase DecNa concentrations, which govern aqueous solution properties derived from macroscopic isotherms, such as surface tension and vapor pressure suppression, may therefore be much smaller than the total evaluated aqueous phase concentrations. Indeed, previous work find no evidence of droplet activation being limited by organic bulk solubility, for neither pure DecNa, nor for mixed DecNa and $\mathrm{NaCl}$ particles (Prisle et al., 2008, 2010b). On the other hand, the sample solutions forming the liquid jet in the XPS experiments are much larger aqueous systems than the submicron activating droplets and consequently do not experience significant bulk phase depletion of DecNa. The solution concentrations investigated in the XPS experiments are therefore comparable to and highly representative of aqueous droplets involved in cloud formation, precipitation, and cloud processing in the atmosphere. Droplets comprising soluble inorganics like ammonium sulfate tend to activate as even more dilute solutions than those containing only organics. However, depletion of dissolved surfactant by surface adsorption will alter the relative bulk phase mixing ratio of organics and (non-surfactant) inorganics, yielding much enhanced inorganic fractions in the droplet bulk, compared to the roughly even overall organicinorganic mixture of particles containing little or no water. It is therefore of immediate interest to investigate properties of ternary aqueous organic surfactant-inorganic salt mixtures in the range of much higher salt ratios, as well as potentially at even lower total aqueous concentrations, than in the present XPS experiments.

We emphasize again that our present findings pertain to aqueous phase systems and in particular to mixtures of the decanoate-decanoic acid pair with the inorganic $\mathrm{Na}^{+}, \mathrm{NH}_{4}^{+}$, $\mathrm{Cl}^{-}$, and $\mathrm{SO}_{4}^{2-}$ ions. Since the more concentrated solutions studied are observed to be close to the aqueous bulk solubility limit of decanoate, higher concentrations are not expected to be found in the aqueous phase in atmospheric systems, at least not at equilibrium conditions. More concentrated solutions may of course still exist as metastable supersaturated phases. Atmospheric organics display wide ranges of aqueous bulk solubilities, but quantitative information on the exact values and their variation with mixing state and temperature within the aerosol phase is particularly scarce. A miscibility gap may exist between water and organic aerosols, separating distinct stable regions of their mixing diagram into an organic phase with water dissolved and an aqueous phase with dissolved organics (Prisle et al., 2010a, e.g.). The different components of such organic-inorganic-water aerosol mixtures may likely behave highly non-linearly over the full range of possible mixing states. An extrapolation of the re- sults presented in this work to other concentration ranges, mixing states, or chemical species is therefore not intended. For example, salting-out by common counter cations like $\mathrm{Na}^{+}$could very likely be more significant for larger mixing ratios of the inorganic salt relative to organics like DecNa. And for highly concentrated aerosol, where small amounts of water are absorbed into an organic phase, possibly mixed with inorganics, we have no reason to expect that the effects observed here will be manifest in the same form. To study such systems would require different methods than those applied here. Nevertheless, as argued above, we do believe that the effects described in this work are highly relevant for and indeed occurring within the atmosphere. Thus, we suggest that the potential implications for aerosol properties and their climate effects should be investigated further.

As mentioned, adsorption of carboxylic compounds in aqueous surfaces, and their speciation from protonation and protolysis, may have significant implications for a number of important atmospheric processes involving aqueous aerosol particles. In the following, we briefly describe some of these anticipated mechanisms, related to (1) heterogeneous reactivity in the condensed aerosol surface, and thus aerosol mass formation and atmospheric chemical processing, and (2) thermodynamics of atmospheric phase transformation, in terms of aerosol hygroscopic growth and cloud drop and ice nucleation. These processes in turn govern aerosol mass, properties, lifetimes and influence on atmospheric composition, and thus intricately connect to various major climate impacts of atmospheric aerosols. This is by no means an exhaustive list of processes and their interrelations, just as the evaluation of the relative and overall magnitudes of their effects is left for future work.

We demonstrate here that mixing with different common inorganic salts in the aqueous phase can affect total surface adsorption and acid/base functionality of the decanoate/decanoic acid pair in distinct ways. The observed increase in total organic surface adsorption by co-adsorption of additional acid molecules may affect heterogeneous reactivity of aqueous droplets both by enhanced total surface concentrations, and by changing the functional group mixture presented to gas-phase reactants. In this case the relative speciation of a carboxylate/carboxylic acid pair could specifically affect the immediate (potentially non-equilibrium) aerosol heterogeneous reactivity towards gas-phase species with (Brønsted) acid/base character, for instance ammonia $\left(\mathrm{NH}_{3}\right)$ and higher order amines $\left(\mathrm{R}_{\mathrm{n}} \mathrm{NH}_{3-\mathrm{n}}\right)$. This will in turn affect the atmospheric processing of these species, and importantly the reactive uptake to the aerosol phase and hence the formation of aerosol mass. Furthermore, reaction pathways and rates for such organic species in the atmosphere may be greatly affected by their uptake to the condensed phase, as opposed to remaining in the gas phase. These processes and their surface specificity are in turn expected to depend on aerosol $\mathrm{pH}$ and the acid strength of adsorbed surface active organic species. 
As an example, depending on the relative rates of diffusion and the different chemical reactions involved, $\mathrm{NH}_{3}$ generated from $\mathrm{NH}_{4}^{+}$in the aerosol surface according to Eq. (4) could be lost to the gas phase, as was indeed observed in the present XPS experiments (see Fig. 4), and subsequently replaced by larger organic amines forming substituted ammonium ions $\left(\mathrm{R}_{\mathrm{n}} \mathrm{NH}_{4-\mathrm{n}}^{+}\right)$that dissolve into the aqueous aerosol bulk phase. Ammonia lost by out-gassing would then on the other hand be available for chemical "recycling" in the atmosphere. The original aerosol mass loss from out-gassing of generated $\mathrm{NH}_{3}$ is not expected to be dramatic, in case of similarly low solute concentrations, in particular for organics with low water solubilities. However, dissolved $\mathrm{R}_{\mathrm{n}} \mathrm{NH}_{4-\mathrm{n}}^{+}$salts generated from gas-phase species with bulky substituents $(\mathrm{R})$ could add significant mass to the aerosol phase, facilitated by much higher expected aqueous solubilities of the ions compared to the corresponding molecular forms.

Increased aerosol mass, especially from increasing dissolved aqueous ion concentrations is expected to affect aerosol hygroscopicity and cloud condensation nuclei $(\mathrm{CCN})$ and ice nuclei (IN) activity from an increased Raoult effect (Pruppacher and Klett, 1997). However, the effect on water activity of non-ideal interactions in the aqueous phase remains to be firmly constrained for many of the solutes comprised in atmospheric aerosol. Furthermore, the thermodynamic framework for the various ice nucleation processes awaits further development in order to evaluate the effect of chemical composition and aqueous phase interactions. Aerosol hygroscopicity and cloud drop and ice nucleation may in turn greatly influence the addition of aerosol mass from uptake of gas-phase water, as well as formation of cloud droplets and ice crystals, and their eventual removal by precipitation, and thus the total atmospheric suspended aerosol burden.

The extent of organic surface adsorption will also affect aerosol hygroscopic and cloud and ice forming properties, by influencing the corresponding total amount of dissolved species remaining in the aqueous bulk phase and hence the bulk water activity. The amount of adsorbed surfactant and the speciation onto different chemical forms will likely also affect aqueous droplet surface tension. As is seen for decanoate/decanoic acid, the different forms of long-chain corresponding carboxylate/carboxylic acid pairs may have significantly different surfactant properties, in terms of both surface adsorption and surface tension reducing potential. In addition, synergetic effects on solution surface tension may arise from the simultaneous adsorption of several surfactant species. In submicrometer aqueous droplets, the observed $25 \%$ enhancement of organic surface abundances is expected to further enhance bulk phase depletion and thus act to decrease droplet $\mathrm{CCN}$ potential. The effect of co-adsorption of the more surface active form of the decanoate/decanoic acid pair is on the other hand to decrease aqueous surface tension, which in turn would facilitate droplet $\mathrm{CCN}$ activation. The resulting hygroscopicity and $\mathrm{CCN}$ activity could be ei- ther enhanced or impeded by the combined effects on total surface adsorption and aqueous surface tension, depending both on the relative magnitudes of these mechanisms, as well as other intrinsic aerosol characteristics (Prisle et al., 2010b, 2011, 2012). Similar effects on aerosol IN activity have to our knowledge not yet been investigated.

These implications pertain to the current level of understanding and description of mechanisms affected by surface adsorption properties and speciation, from the process-level to the global scale. For example, activating cloud droplets are typically such dilute aqueous systems that non-ideal interactions are assumed not to affect their $\mathrm{CCN}$ properties. Here, we nevertheless see evidence of non-ideality for solutions of compositions immediately comparable to dilute droplets in the atmosphere. To properly capture non-ideal organic/inorganic solute interactions, process-level models of cloud microphysics would need to use multi-component surface tension isotherms, or in other ways account for the enhanced organic activity coefficients in droplet solutions. Furthermore, fatty acids and their salts are found in atmospheric aerosol from all environments, whereas the common inorganic salts sodium chloride and ammonium sulfate are often related to marine and continental/urban environments, respectively. Differences in surface adsorption and speciation of organic surfactants, when mixed with these different inorganic salts, may affect properties of atmospheric aqueous aerosol, such as $\mathrm{CCN}$ activation, in environment-specific ways that are not accounted for in current state-of-the-art atmospheric models. In particular, our present findings highlight the problematics of using (too) simple proxy systems to represent the properties and capture their responses to changes for atmospheric aerosol comprising a very wide range of chemical species and mixing states. We see that for some important processes, inorganic salt may not just be any salt.

The atmospheric system is generally not in equilibrium, on either the chemical and microphysical process-level, or even on regional scales. The actual atmospheric implications of these speculated effects will all be crucially dependent upon the relative time scales of the numerous processes involved. Correct predictions of general circulation atmospheric and climate models are therefore innately limited by their ability to properly capture such processes and their relative importance on the various time scales in question. For the investigated solutions as model systems for atmospheric aerosols, directly probing the aqueous surface phase is greatly advantageous, compared to approaches based on inferring surface composition and properties from bulk-phase measurements. No implicit assumptions regarding equilibrium between the surface and bulk phases, or validity of specific adsorption isotherms, are imposed upon obtaining our present results. From a perspective of atmospheric modelling, we believe this will eventually lead to much better constrained characterizations and more robust parametrizations of the properties in question, than those based on results derived from 
(computationally expensive) iterative procedures. The phenomena observed here may have significant implications for important aqueous solution properties, such as surface tension, via mechanisms which are not explicitly accounted for in the current macroscopic framework.

We present results that provide new insights into the properties of aqueous solution surfaces of immediate atmospheric relevance. This work thus clearly demonstrates the viability of the synchrotron-based XPS technique for studying such systems. Photoelectron spectroscopy even has the potential for probing the detailed interactions responsible for these surface phenomena directly on the molecular level (Ottosson et al., 2011b).

\section{Conclusions}

We have characterized the surfaces of dilute binary aqueous solutions of the organic surfactant sodium decanoate, and ternary mixtures of sodium decanoate with four different inorganic salts, sodium chloride, ammonium sulfate, sodium sulfate, and ammonium chloride, using synchrotron based Xray photoelectron spectroscopy (XPS). All solutes are common constituents of atmospheric aerosol particles.

We found that the sodium and chloride ions had no influence on the relative speciation of the decanoate anion and its corresponding decanoic acid in the aqueous surface, nor did these inorganic ions influence the individual adsorption properties of the different forms of the organic surfactant. Notably, no significant salting-out effect from common sodium cations of the organic and inorganic salts was observed. There are indications of decanoate salting-out by increased ionic strength in sulfate solutions, but our present results are not conclusive. Instead, mixing with ammonium cations significantly enhanced the surface abundances of decanoic acid. This decanoic acid enhancement is caused by surfacespecific protonation of decanoate by the weakly acidic ammonium ions, but does not occur at the expense of the decanoate surface abundance. Mixing with ammonium ions thus leads to more surfactant molecules in total being present in the topmost surface region of the solution.

Surface activity of some components in aqueous solution is a central, yet often not well-constrained, property determining the processing of atmospheric organic aerosols. XPS is highly surface and chemically specific, and thus ideal for direct characterization of surfactant properties and speciation in solution surfaces. Here, we have presented results of XPS experiments for aqueous solutions of organic-inorganic mixtures and at dilute concentrations, comparable to those found in the atmosphere. Our results elegantly demonstrate the successful application of XPS to solutions of immediate atmospheric relevance, and yield directly measured characterizations that shed new light to the molecular properties and interactions within the investigated aqueous surfaces. The novel results potentially have significant implications for a number of processes critical to the climate effects of aqueous aerosol, which will be the focus of future work.

\section{Supplementary material related to this article is available online at: http://www.atmos-chem-phys.net/12/ 12227/2012/acp-12-12227-2012-supplement.pdf.}

Acknowledgements. The authors acknowledge the NordForsk researcher network project 10160 NICITA, the Knut and Alice Wallenberg Foundation (KAW), and the Swedish Research Council (VR) for funding. N. L. Prisle gratefully acknowledges the funding received for this work from the Carlsberg Foundation (personal grants 2009_01_0366 and 2010_01_0391).

Edited by: M. Amman

\section{References}

Bässler, M., Forsell, J.-O., Björneholm, O., Feifel, R., Jurvansuu, M., Aksela, S., Sundin, S., Sorensen, S. L., Nyholm, R., Ausmees, A., and Svensson, S.: Soft X-ray undulator beam line I411 at MAX-II for gases, liquids and solid samples, J. Electron Spectrosc. Relat. Phenom., 953, 101-103, 1999.

Bergersen, H., Marinho, R. R. T., Pokapanich, W., Lindblad, A., Björneholm, O., Saethre, L. J., and Öhrwall, G.: A photoelectron spectroscopic study of aqueous tetrabutylammonium iodide, J. Phys.: Cond. Matt., 19, 326101, doi:10.1088/09538984/19/32/326101, 2007.

Burden, D. K., Johnson, A. M., and Nathanson, G. M.: Electronic Structures of Formic Acid $(\mathrm{HCOOH})$ and Formate $(\mathrm{HCOO})$ in Aqueous Solutions, J. Phys. Chem. A, 113, 14131-14140, 2009.

Campbell, A. N. and Lakshminarayanan, G. R.: Conductances and Surface Tensions of Aqueous Solutions of Sodium Decanoate Sodium Laurate and Sodium Myristate at $25{ }^{\circ} \mathrm{C}$ and $35^{\circ} \mathrm{C}$, Canad. J. Chem., 43, 1729-1737, 1965.

Campbell, J. L. and Papp, T.: Widths of the atomic K-N7-levels, Atom. Data Nucl. Data Tables, 77, 1, 2001.

Cheng, Y., Li, S.-M., Leithead, A., Brickell, P. C., and Leaitch, W. R.: Characterizations of cis-pinonic acid and n-fatty acids on fine aerosols in the Lower Fraser Valley during Pacific 2001 Air Quality Study, Atmos. Environ., 38, 5789-5800, 2004.

Dempsey, L. P., Brastad, S. M., and Nathanson, G. M.: Interfacial Acid Dissociation and Proton Exchange Following Collisions of DCl with Salty Glycerol and Salty Water, J. Phys. Chem. Lett., 2, 622-627, 2011

Dinar, E., Taraniuk, I., Graber, E. R., Katsman, S., Moise, T., Anttila, T., Mentel, T. F., and Rudich, Y.: Cloud Condensation Nuclei properties of model and atmospheric HULIS, Atmos. Chem. Phys., 6, 2465-2482, doi:10.5194/acp-6-2465-2006, 2006a.

Earnshaw, J. C., Nugent, C. P., Lunkenheimer, K., and Hirte, R.: Transitional Behavior in Adsorbed Layers of n-Decanoic Acid at the Air/Water Interface, J. Phys. Chem., 100, 5004-5010, 1996.

Facchini, M., Mircea, M., Fuzzi, S., and Charlson, R.: Cloud Albedo Enhancement by Surface-Active Organic Solutes in Growing Droplets, Nature, 401, 257-259, 1999. 
Facchini, M., Decesari, S., Mircea, M., Fuzzi, S., and Loglio, G.: Surface Tension of Atmospheric Wet Aerosol and Cloud/Fog Droplets in Relation to their Organic Carbon Content and Chemical Composition, Atmos. Environ., 34, 4853-4857, 2000.

Fainerman, V. B., Miller, R., and Möhwald, H.: General Relationships of the Adsorption Behavior of Surfactants at the Water/Air Interface, J. Phys. Chem. B, 106, 809-819, 2002.

Gibbs, J., Bumstead, H., Longley, W., and Name, R. V.: The Collected Works of J. Willard Gibbs, Longmans, Green and Co., 1928.

Gill, P. S., Graedel, T. E., and Weschler, C. J.: Organic Films on Atmospheric Aerosol-Particles, Fog Droplets, Cloud Droplets, Raindrops, and Snowflakes, Rev. Geophys. Space Phys., 21, 903-920, 1983.

Gragson, D. E., McCarty, B. M., and Richmond, G. L.: Surfactant/Water Interactions at the Air/Water Interface Probed by Vibrational Sum Frequency Generation, J. Phys. Chem., 100, 14272-14275, 1996.

Guyot-Sionnest, P., Hunt, H., and Shen, Y. R.: Sum-Frequency Vibrational Spectroscopy of a Langmuir Film: Study of Molecular Orientation of a Two-Dimensional System, Phys. Rev Lett., 59, 1597, 1987.

Hirte, R. and Lunkenheimer, K.: Surface Equation of State and Transitional Behavior of Adsorption Layers of Soluble Amphiphiles at Fluid Interfaces, J. Phys. Chem., 100, 13786-13793, 1996.

Hüfner, S.: Photoelectron spectroscopy, Springer Verlag, Berlin, 1995.

IPCC: Climate Change 2007, The Physical Science Basis, Contribution of Working Group I to the Fourth Assessment Report of the Intergovernmental Panel on Climate Change, Cambridge University Press, New York, 2007.

Kimura, K.: Handbook of He I photoelectron spectra of fundamental organic molecules, Japan scientific societies press, Tokyo, 1981.

Kiss, G., Tombacz, E., and Hansson, H.-C.: Surface Tension Effects of Humic-Like Substances in the Aqueous Extract of Tropospheric Fine Aerosol, J. Atmos. Chem., 50, 279-294, 2005.

Kjaer, K., Als-Nielsen, J., Helm, C. A., Tippman-Krayer, P., and Mobwald, H.: Synchrotron X-ray Dlff raction and Reflection Studies of Arachidic Acid Monolayers at the Air-Water Interface, J. Phys. Chem., 93, 3200-3206, 1989.

Lewis, T., Winter, B., Stern, A. C., Baer, M. D., Mundy, C. J., Tobias, D. J., and Hemminger, J. C.: Does Nitric Acid Dissociate at the Aqueous Solution Surface?, J. Phys. Chem. C, 115, 2118321190, 2011.

Liang, M.: X-ray Diffraction Rotational Microrheology, ProQuest Dissertations And Theses; Thesis (Ph.D.), University of Illinois at Urbana-Champaign, http://books.google.se/books?id= dTkLwbT5kpQC, 2008.

Lide, D. R.: CRC Handbook of Chemistry and Physics, CRC Press LLC, 85th edn., 2004.

Lin, B., McCormick, A. V., Davis, H. T., and Strey, R.: Solubility of sodium soaps in aqueous salt solutions, Journal of Colloid and Interface Science, 291, 543-549, 2005.

Luepakdeesakoon, B., Saiwan, C., and Scamehorn, J. F.: Contact Angle of Surfactant Solutions on Precipitated Surfactant Surfaces. III. Effects of Subsaturated Anionic and Nonionic Surfactants and $\mathrm{NaCl}$, J. Surf. Deter., 9, 125-136, 2006.
Lunkenheimer, K. and Hirte, R.: Another Approach to a Surface Equation of State, J. Phys. Chem., 96, 8683-8686, 1992.

Mills, B. E., Martin, R. L., and Shirley, D. A.: Further Studies of the Core Binding Energy-Proton Affinity Correlation in Molecules, J. Am. Chem. Soc., 98, 2380, 1976.

Mochida, M., Kitamori, Y., Kawamura, K., Nojiri, Y., and Suzuki, K.: Fatty acids in the marine atmosphere: Factors governing their concentrations and evaluation of organic films on seasalt particles, Journal of Geophysical Research, 107, 4325, doi:10.1029/2001JD001278, 2002.

Murphy, D. M., Cziczo, D. J., Froyd, K. D., Hudson, P. K., Matthew, B. M., Middlebrook, M., Peltier, R. E., Sullivan, A., Thomson, D. S., and Weber, R. J.: Single-particle mass spectrometry of tropospheric aerosol particles, J. Geophys. Res., 111, D23S32, doi:10.1029/2006JD007340, 2006.

Nathanson, G. M.: Molecular beam studies of gas-liquid interfaces, Annu. Rev. Phys. Chem., 55, 231-55, 2004.

O’Dowd, C. D., Facchini, M. C., Cavalli, F., Ceburnis, D., Mircea, M., Decesari, S., Fuzzi, S., Yoon, Y. J., and Putaud, J.-P.: Biogenically driven organic contribution to marine aerosol, Nature, 431, 676-680, 2004.

Onorato, R. M., Otten, D. E., and Saykally, R. J.: Measurement of Bromide Ion Affinities for the Air/Water and Dodecanol/Water Interfaces at Molar Concentrations by UV Second Harmonic Generation Spectroscopy, J. Phys. Chem. C, 114, 13746-13751, 2010.

Ottosson, N., Børve, K. J., Spångberg, D., Sæthre, L. J., Faubel, M., Bergersen, H., Pokapanich, W., Öhrwall, G., Björneholm, O., and Winter, B.: Cations Strongly Reduce Electron-Hopping Rates in Aqueous Solutions, J. Am. Chem. Soc., 133, 3120, 2011 a.

Ottosson, N., Wernersson, E., Söderström, J., Pokapanich, W., Kaufmann, S., Svensson, S., Persson, I., Öhrwall, G., and Björneholm, O.: The protonation state of small carboxylic acids at the water surface from photoelectron spectroscopy, Phys. Chem. Chem. Phys., 13, 12261-12267, 2011 b.

Powell, C. J. and Jablonski, A.: Constraining Particle Evolution from Wall Losses, Coagulation, and Condensation-Evaporation in Smog-Chamber Experiments: Optimal Estimation Based on Size Distribution Measurements, Nucl. Instr. Meth. Phys. Res. A, 601, 54-65, 2009.

Prisle, N. L., Raatikainen, T., Sorjamaa, R., Svenningsson, B., Laaksonen, A., and Bilde, M.: Surfactant partitioning in cloud droplet activation: a study of C8, C10, C12 and C14 normal fatty acid sodium salts, Tellus, 60B, 416-431, doi:10.1111/j.16000889.2008.00352.x, 2008.

Prisle, N. L., Engelhart, G. J., Bilde, M., and Donahue, N. M.: Humidity Influence on Gas-Particle Phase Partitioning of $\alpha$ Pinene $+\mathrm{O}_{3}$ Secondary Organic Aerosol, Geophys. Res. Lett., 37, L01802, doi:10.1029/2009GL041402, 2010a.

Prisle, N. L., Raatikainen, T., Laaksonen, A., and Bilde, M.: Surfactants in cloud droplet activation: mixed organic-inorganic particles, Atmos. Chem. Phys., 10, 5663-5683, doi:10.5194/acp-105663-2010, 2010b.

Prisle, N. L., Dal Maso, M., and Kokkola, H.: A simple representation of surface active organic aerosol in cloud droplet formation., Atmos. Chem. Phys., 11, 4073-4083, doi:10.5194/acp-11-40732011, 2011.

Prisle, N. L., Asmi, A., Topping, D., Partanen, A.-I., Romakkaniemi, S., Dal Maso, M., Kulmala, M., Laaksonen, A., 
Lehtinen, K. E. J., McFiggans, G., and Kokkola, H.: Surfactant effects in global simulations of cloud droplet activation., Geophys. Res. Lett., 39, L05802, doi:10.1029/2011GL050467, 2012.

Pruppacher, H. and Klett, J.: Microphysics of Clouds and Precipitation, Kluwer Academic Publishers, second revised and enlarged edn., 1997.

Robinson, R. and Stokes, R.: Electrolyte Solutions, Dover Publications, Inc., second revised edn., 2002.

Roszak, S., Gee, R. H., Balasubramanian, K., and Fried, L. E.: New theoretical insight into the interactions and properties of formic acid: Development of a quantum-based pair potential for formic acid, J. Chem. Phys., 123, 144702, doi:10.1063/1.2052707, 2005.

Seinfeld, J. H. and Pandis, S. N.: Atmospheric Chemistry and Physics - From Air Pollution to Climate Change, John Wiley and Sons, Inc., second edn., 2006.

Söderström, J., Mårtensson, N., Travnikova, O., Patanen, M., Miron, C., Sæthre, L. J., Bærve, K. J., Rehr, J. J., Kas, J. J., Vila, F. D., Thomas, T. D., and Svensson, S.: Nonstoichiometric Intensities in Core Photoelectron Spectroscopy, Phys. Rev Lett., 108, 193005, 2012.

Sorjamaa, R., Svenningsson, B., Raatikainen, T., Henning, S., Bilde, M., and Laaksonen, A.: The role of surfactants in Köhler theory reconsidered, Atmos. Chem. Phys., 4, 2107-2117, doi:10.5194/acp-4-2107-2004, 2004.

Stahl, P. H. and Wermuth, C. G.: Handbook of Pharmaceutical Salts, Properties, Selection and Use, Wiley-VCH and Verlag Helvetica Chimica Acta, Switzerland, 2002.

Tabazadeh, A.: Organic aggregate formation in aerosols and its impact on the physicochemical properties of atmospheric particles, Atmos. Environ., 39, 5472-5480, 2005.

Tang, C. Y. and Allen, H. C.: Ionic Binding of Na+ versus $\mathrm{K}+$ to the Carboxylic Acid Headgroup of Palmitic Acid Monolayers Studied by Vibrational Sum Frequency Generation Spectroscopy, J. Phys. Chem. A, 113, 7383-7393, 2009.

Tuckermann, R.: Surface tension of aqueous solutions of watersoluble organic and inorganic compounds, Atmos. Environ., 41, 6265-6275, 2007.
Vanhanen, J., Hyvärinen, A.-P., Anttila, T., Raatikainen, T., Viisanen, Y., and Lihavainen, H.: Ternary solution of sodium chloride, succinic acid and water; surface tension and its influence on cloud droplet activation, Atmos. Chem. Phys., 8, 4595-4604, doi:10.5194/acp-8-4595-2008, 2008.

Voss, L. F., Hadad, C. M., and Allen, H. C.: Competition between Atmospherically Relevant Fatty Acid Monolayers at the Air/Water Interface, J. Phys. Chem. B, 110, 19487-19490, 2006.

Wen, X. Y., Lauterbach, J., and Franses, E. I.: Surface densities of adsorbed layers of aqueous sodium myristate inferred from surface tension and infrared reflection absorption spectroscopy, Langmuir, 16, 6987-6994, 2000.

Winter, B. and Faubel, M.: Photoemission from Liquid Aqueous Solutions, Chem. Rev., 106, 1176-1211, 2006.

Winter, B., Weber, R., Widdra, W., Dittmar, M., Faubel, M., and Hertel, I. V.: Full Valence Band Photoemission from Liquid Water Using EUV Synchrotron Radiation, J. Phys. Chem. A, 108, 2625-2632, 2004.

Yeh, J. J. and Lindau, I.: Atomic subshell photoionization cross sections and asymmetry parameters: 1 leq $\mathrm{Z}$ leq 103, Atomic and Nuclear Data Tables, 32, 1-155, 1985.

Zhang, Q., Jimenez, J. L., Canagaratna, M. R., Allan, J. D., Coe, H., Ulbrich, I., Alfarra, M. R., Takami, A., Middlebrook, A. M., Sun, Y. L., Dzepina, K., Dunlea, E., Docherty, K., DeCarlo, P. F., Salcedo, D., Onasch, T., Jayne, J. T., Miyoshi, T., Shimono, A., Hatakeyama, S., Takegawa, N., Kondo, Y., Schneider, J., Drewnick, F., Borrmann, S., Weimer, S., Demerjian, K., Williams, P., Bower, K., Bahreini, R., Cottrell, L., Griffin, R. J., Rautiainen, J., Sun, J. Y., Zhang, Y. M., and Worsnop, D. R.: Ubiquity and dominance of oxygenated species in organic aerosols in anthropogenically-influenced Northern Hemisphere midlatitudes, Geophys. Res. Lett., 34, L13801, doi:10.1029/2007GL029979, 2007. 